\title{
Characterization and monitoring of the Åknes rockslide using terrestrial laser scanning
}

\author{
T. Oppikofer ${ }^{1}$, M. Jaboyedoff ${ }^{1}$, L. Blikra ${ }^{2,3}$, M.-H. Derron ${ }^{3}$, and R. Metzger ${ }^{1}$ \\ ${ }^{1}$ Institute of Geomatics and Analysis of Risk (IGAR), University of Lausanne, Switzerland \\ ${ }^{2}$ Åknes/Tafjord Project, Stranda, Norway \\ ${ }^{3}$ Geological Survey of Norway (NGU), Trondheim, Norway
}

Received: 7 January 2009 - Revised: 5 June 2009 - Accepted: 5 June 2009 - Published: 26 June 2009

\begin{abstract}
Terrestrial laser scanning (TLS) provides highresolution point clouds of the topography and new TLS instruments with ranges exceeding $300 \mathrm{~m}$ or even $1000 \mathrm{~m}$ are powerful tools for characterizing and monitoring slope movements. This study focuses on the 35 million $\mathrm{m}^{3}$ Åknes rockslide in Western Norway, which is one of the most investigated and monitored rockslides in the world. The TLS point clouds are used for the structural analysis of the steep, inaccessible main scarp of the rockslide, including an assessment of the discontinuity sets and fold axes. TLS acquisitions in 2006, 2007 and 2008 provide information on 3 -D displacements for the entire scanned area and are not restricted like conventional survey instruments to single measurement points. The affine transformation matrix between two TLS acquisitions precisely describes the rockslide displacements and enables their separation into translational components, such as the displacement velocity and direction, and rotational components, like toppling. This study shows the ability of TLS to obtain reliable 3-D displacement information over a large, unstable area. Finally, a possible instability model for the upper part of Åknes rockslide explains the measured translational and rotational displacements by a combination of southward planar sliding along the gneiss foliation, gravitational vertical settlement along the complex, stepped basal sliding surface and northward toppling toward the opened graben structure.
\end{abstract}

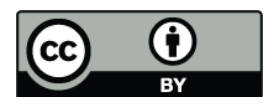

Correspondence to: T. Oppikofer (thierry.oppikofer@unil.ch)

\section{Introduction}

Landslides are a major natural hazard in many mountainous regions (Evans and Clague, 1994). In Norway, large rockslides causing catastrophic tsunamis in the narrow fjords are frequent. In the Storfjord in Western Norway, several historical reports and rock avalanche deposits in the fjord give evidence to this high frequency with approximately one catastrophic rockslide event every 100 years (Blikra et al., 2005, 2006c). In 1934 the 2-3 million $\mathrm{m}^{3}$ Tafjord rockslide led to a catastrophic tsunami with a run-up height of more than $60 \mathrm{~m}$ and killing 40 people in the villages of Fjøra and Tafjord (Fig. 1a) (Bugge, 1937; Kaldhol and Kolderup, 1937; Braathen et al., 2004). This high rockslide density and frequency is explained by the high relief created by high post-glacial uplift rates and fjord incision along pre-existing structures (Redfield et al., 2005; Blikra et al., 2006c; Henderson et al., 2006). Glacial debuttressing and subsequent stress-release are potential causes that led to the destabilization of the fjord flanks and the creation of rockslides (Agliardi et al., 2001; Ballantyne, 2002; Ambrosi and Crosta, 2006; Blikra et al., 2006c).

The Åknes rockslide (Fig. 1b, c) is situated on the western flank of Sunnylvsfjord, a branch of the Storfjord (Fig. 1a). Dozens of cruise ships with thousands of tourists onboard pass every summer beneath the Åknes rockslide on their way to the scenic Geirangerfjord, which is listed in the UNESCO's world heritage sites. The volume of the Åknes rockslide was first estimated to be 5 to 6 million $\mathrm{m}^{3}$ (Norwegian Geotechnical Institute, 1992, 1996; Braathen et al., 2004). Detailed investigations however revealed that the whole rockslide covers a much larger area (approximately $550^{\prime} 000 \mathrm{~m}^{2}$ ) and stretches from $900 \mathrm{~m}$ down to $100 \mathrm{~m}$ above sea level (Blikra, 2008). The new volume was estimated to

Published by Copernicus Publications on behalf of the European Geosciences Union. 

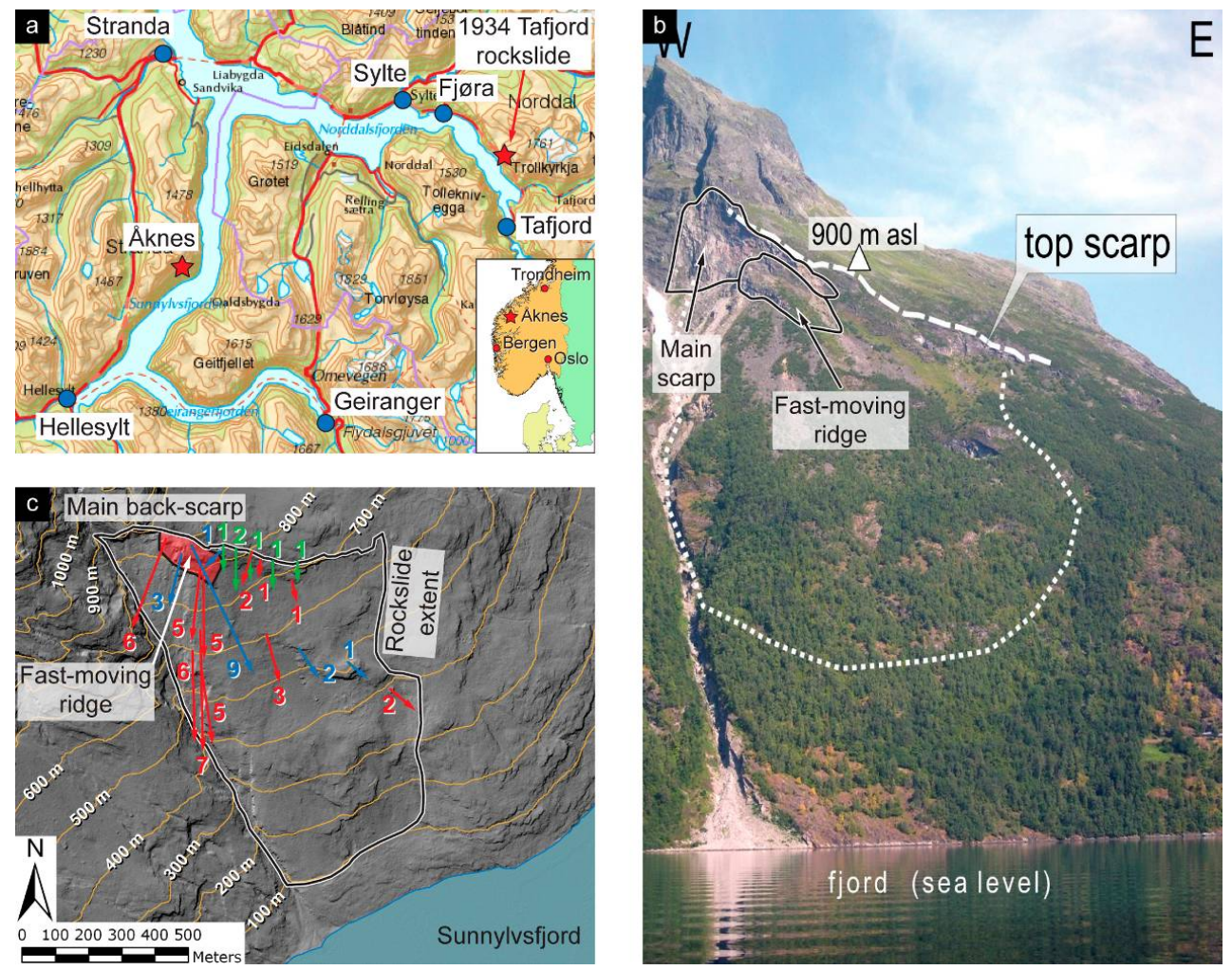

Fig. 1. (a) Location map of the Åknes rockslide in Western Norway (ㄷ Statens Kartverk, Norwegian Mapping Authority); (b) picture of the Åknes rockslide seen from the Sunnylvsfjord showing the areas of interest (modified from Derron et al., 2005); (c) shaded relief map of the rockslide showing its extent, the location of the main scarp and the fast-moving ridge, as well as the annual displacement vectors in $\mathrm{cm} / \mathrm{year}$ obtained by GPS (blue), extensometers (green) and total station (red) (displacement data from Ganerød et al. (2008); ALS digital elevation model (C) Åknes/Tafjord Project, 2005).

30-40 million $\mathrm{m}^{3}$ (Blikra et al., 2006b; Blikra, 2008). Its failure might cause a catastrophic tsunami in the fjord that would reach the nearby villages of Hellesylt and Geiranger (Fig. 1a) within 4 and 10 min, respectively, creating run-up waves of up to $40 \mathrm{~m}$ in these localities (Blikra et al., 2005; Eidsvig and Harbitz, 2005; Blikra et al., 2006c).

Since 2005, the Åknes rockslide has been investigated and monitored as part of the Åknes/Tafjord Project (www.aknes-tafjord.no). It is one of the biggest landslide monitoring projects in the world employing a multitude of geological, structural, geophysical and borehole investigations (Blikra et al., 2006a; Blikra, 2008; Ganerød et al., 2008; Roth and Blikra, 2009). The monitoring focuses not only on the measurement of slope movements using a large variety of techniques (Kveldsvik et al., 2006), but also includes measurements of meteorological, seismic and groundwater conditions (Blikra et al., 2006a; Blikra, 2008; Roth and Blikra, 2009). Some displacement monitoring techniques are point based (GPS, extensometers, total station, and laser distance meters), while others are area based (photogrammetry, satellite-based and ground-based radar interferometry, aerial laser scanning (ALS), and TLS). Point based measurements are generally more accurate and precise than area based techniques, especially when control targets are used. However, point based measurements provide only information on a few selected monitoring points and not on the whole landslide (Bitelli et al., 2004). The measured slope movements reach about 1-3 cm/year (Braathen et al., 2004; Derron et al., 2005; Kveldsvik et al., 2006; Ganerød et al., 2008), but higher annual displacements are recorded in the most unstable parts (7-20 cm/year) (Blikra et al., 2006b) (Fig. 1c).

Through its capability to obtain point clouds of the topography, TLS is widely used nowadays for detection and monitoring of deformations or displacements (Gordon et al., 2001; Slob and Hack, 2004; Bauer et al., 2005; Biasion et al., 2005). Applications include the quantification of deformation on man-made structures (Gordon et al., 2001, 2003; Lindenbergh and Pfeifer, 2005; Alba et al., 2006; Tsakiri et al., 2006) and of rockfall in cliff erosion (Lim et al., 2005; Rosser et al., 2005), the back-analysis of a rockfall (Abellán et al., 2006), and structural analyses (Feng and Röshoff, 2004; Slob et al., 2005; Sturzenegger et al., 2007; Metzger and Jaboyedoff, 2008; Lato et al., 2009; Sturzenegger and Stead, 2009) or the measurement of displacements (Bitelli et al., 2004; 

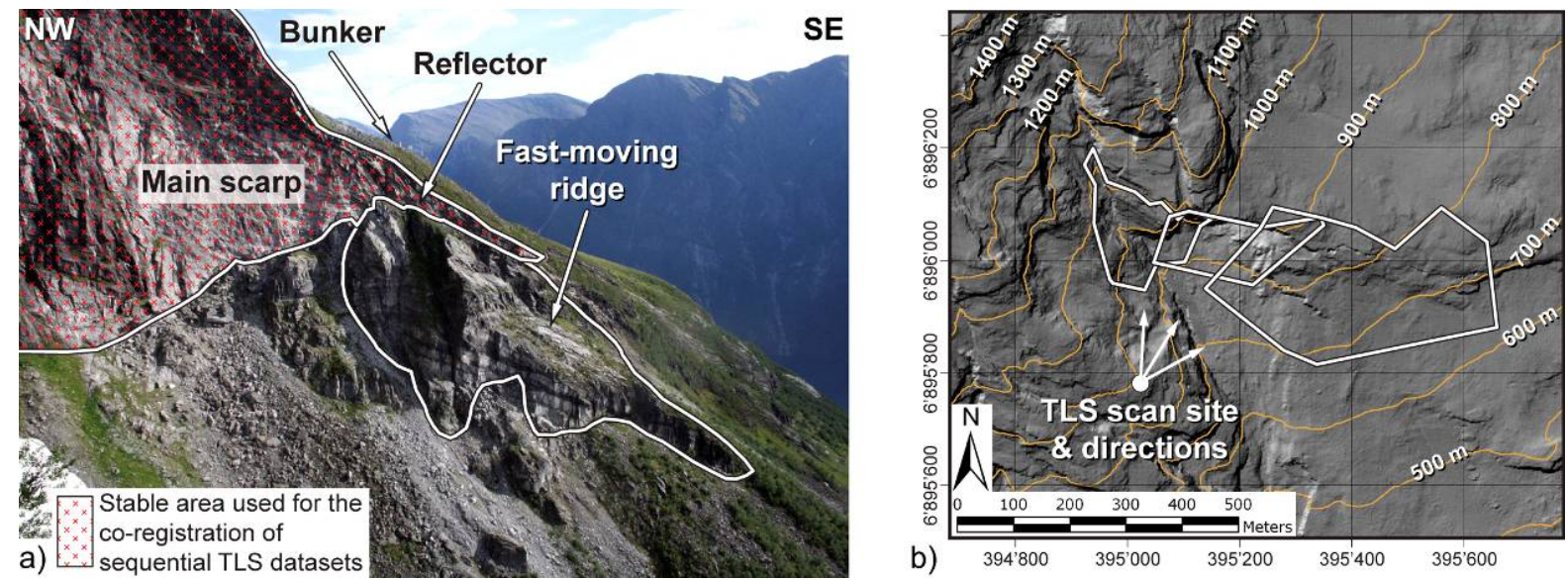

Fig. 2. Photograph of the main scarp and fast-moving ridge of the Åknes rockslide taken from the TLS scan site situated at 300 to $400 \mathrm{~m}$ from the rock wall. The locations of the reflector and the bunker used for the instrument accuracy assessment are indicated; (b) shaded relief map of the upper part of the Åknes rockslide showing the TLS scan site, as well as the scan directions and extent of the area scanned in this study.

Oppikofer et al., 2008a, b; Travelletti et al., 2008; Teza et al., 2008; Abellán et al., 2009). The knowledge of the displacement rates is essential for hazard assessment (Crosta and Agliardi, 2003), especially for the evaluation of volumes, the failure prediction, and the assessment of the tsunami hazard.

A detailed TLS investigation of the Åknes rockslide was undertaken in 2006, 2007 and 2008. The primary goal of this survey was the detection of movements in the uppermost part of the rockslide by comparison of sequential TLS point clouds (time-series) and the structural analysis of the scarp area.

\section{Methodology}

\subsection{Terrestrial laser scanning}

\subsubsection{Technique}

The TLS technology is based on the reflectorless and contactless acquisition of a point cloud of the topography using the time-of-flight distance measurement of an infrared laser pulse (Lichti et al., 2002; Slob and Hack, 2004). The Optech ILRIS-3D used for this study has a wavelength of $1500 \mathrm{~nm}$ and a range in practice of about 600 to $800 \mathrm{~m}$ on rock slopes, depending on the reflectivity of the object. The monochromatic and nearly parallel laser pulse is sent out in a precisely known direction. The pulse gets back-scattered by various objects like the terrain, vegetation, houses and other manmade structures. The scanner then records the back-scattered pulse. The time-of-flight of the signal is then converted into the distance between the scanner and the object. The coordinates of each point relative to the scanner are defined by its distance and the azimuthal (horizontal) and zenithal (ver- tical) angles (Teza et al., 2007). Mirrors inside the scanner allow a $40^{\circ}$ wide and $40^{\circ}$ high field of view to be scanned in a single acquisition with a frequency of about 2500 points per second. The spatial resolution depends on the distance of the object and the chosen angular spacing between two spots.

\subsubsection{Data acquisitions}

On 3 August 2006 a complete point cloud of the upper main scarp and the fast-moving ridge was obtained from the SW rim of the Åknes rockslide area at a distance ranging from $300 \mathrm{~m}$ (main scarp) and $400 \mathrm{~m}$ (bottom of ridge) (Fig. 2). The main scarp and the ridge were scanned again on 10 September 2006, 7 August 2007 and 24 August 2008. The TLS datasets comprise 5.9 to 8.1 million points and the resulting mean point spacing $\delta$ (or resolution) on the rock face ranges between $7.9 \mathrm{~cm}$ and $10.5 \mathrm{~cm}$ at a distance of $300 \mathrm{~m}$ and $400 \mathrm{~m}$, respectively.

\subsubsection{Co-registration and georeferencing}

The TLS datasets were treated and analyzed using the PolyWorks software (InnovMetric, 2009). First, the raw scans were manually cleaned to remove any unwanted objects, such as vegetation. The co-registration (or alignment) of the scans is achieved first by a manual alignment, which consists in identifying common points in the different point clouds. Following this rough matching an automated iterative procedure with a point-to-surface Iterative Closest Point (ICP) algorithm (Besl and McKay, 1992; Guarnieri et al., 2006; Teza et al., 2007) is carried out in order to minimize the co-registration errors. An overlap of approximately $20 \%$ between the different scans is necessary to ensure good matching between the datasets. 

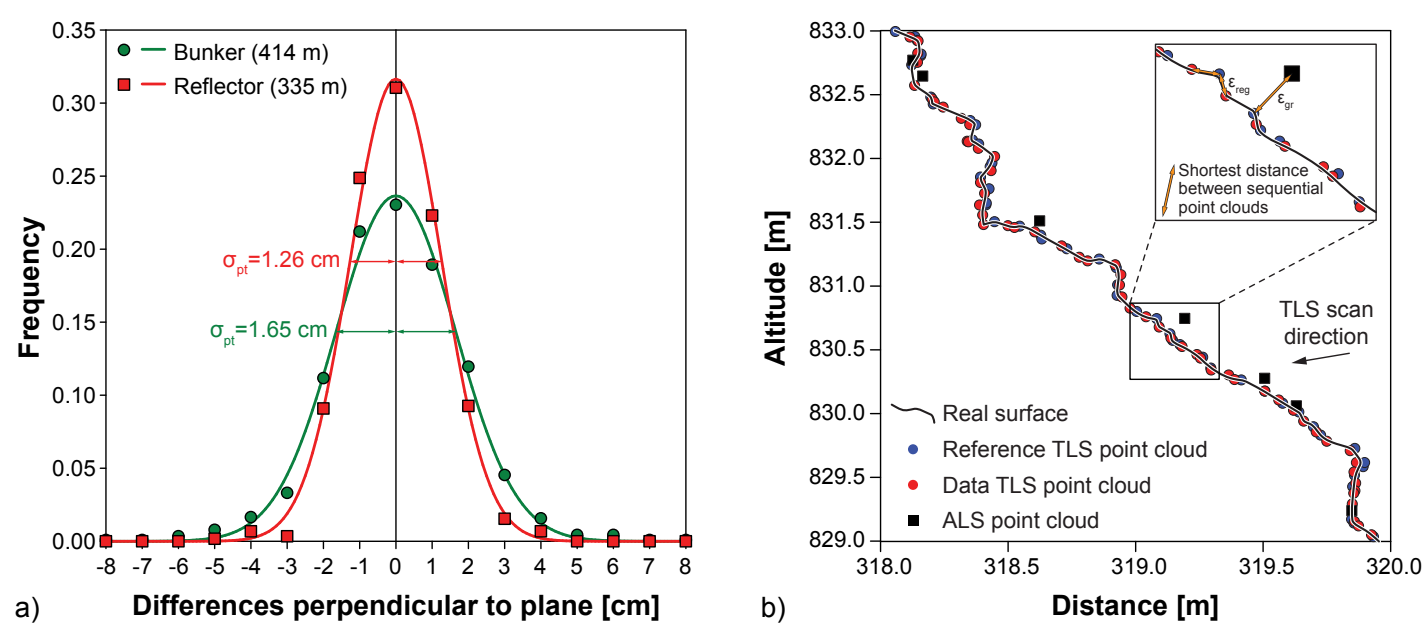

Fig. 3. Error and accuracy assessment of the TLS point cloud and the co-registration procedure: (a) histograms of the error between the TLS data and planes fitted on man-made planar structures. The standard deviations of the Gaussian distributions fitted on the histogram are representative for the instrument accuracy at the given distances; (b) profile across the TLS and ALS point clouds illustrating the coregistration error caused by the spacing between two points and the accuracy of the points. Co-registration errors between data and reference TLS point clouds $\left(\varepsilon_{\text {reg }}\right)$ are mainly due to the point spacing. Georeferencing by co-registration of TLS point clouds on an ALS point cloud leads to positioning errors $\left(\varepsilon_{g r}\right)$ caused by the lower accuracy of the ALS data.

This co-registration procedure is used for individual scans taken at the same epoch, like three scans with different view directions acquired for this study (Fig. 2b), but also for the co-registration of sequential TLS point clouds and for the georeferencing of the TLS datasets. For the georeferencing an ALS point cloud (@ Åknes/Tafjord Project) with an average point spacing of $60 \mathrm{~cm}\left(2.8\right.$ points $\left./ \mathrm{m}^{2}\right)$ was used as reference. The high resolution TLS point clouds complete the ALS digital elevation model (ALS-DEM) that is generally only poorly defined in steep cliffs (Derron et al., 2005).

Sequential TLS point clouds enable the detection and quantification of slope movements, like landslides or rockfalls (Bitelli et al., 2004; Bauer et al., 2005; Rosser et al., 2005; Abellán et al., 2006; Oppikofer et al., 2008a, b; Teza et al., 2008; Travelletti et al., 2008; Abellán et al., 2009). Unlike other studies that compared DEMs created from the georeferenced TLS point clouds to quantify the displacements (Bitelli et al., 2004; Bauer et al., 2005), in this study the sequential point clouds are co-registered with the reference point cloud by limiting the iterative alignment procedure to the assumed stable part around the rockslide only (Teza et al., 2007; Oppikofer et al., 2008a, b). A high percentage of stable areas relative to the moving parts (33\% for the 2006 reference dataset: 2.1 million stable points, 6.4 million points in total, Fig. 2) assures good co-registration of the sequential point clouds.

\subsubsection{Instrumental and co-registration errors assess- ment}

The assessment of the instrumental and data treatment errors is essential for displacement analyses and landslide monitor- ing, since these errors determine the minimum displacement that can be detected by the approach used.

At a distance of $100 \mathrm{~m}$, the instrument accuracy provided by the manufacturer equals approximately $7 \mathrm{~mm}$ for the distance and $8 \mathrm{~mm}$ for the position. The effective error is assessed by fitting planes on man-made planar structures found on the scans, i.e. the wall of a bunker situated above the main scarp at a distance of $414 \mathrm{~m}$ and the foundations of a reflective target on the fast-moving ridge at a distance of $335 \mathrm{~m}$ (Fig. 2), and computing the distance between the points and the planes. These standard deviations on point measurements $\left(\sigma_{p t}\right)$ vary between $1.26 \mathrm{~cm}$ on the reflector foundations and $1.65 \mathrm{~cm}$ on the bunker (Fig. 3a).

The error of the co-registration using the ICP algorithm is mainly dependent on two factors: (1) the point spacing $\delta$ of the two datasets, and (2) the point measurement error $\left(\sigma_{p t}\right)$ (Fig. 3b). As the TLS datasets have a given point spacing $\delta$, it is implicit that not necessarily the same points on an irregular surface are measured and consequently two neighbouring points in different scans are separated by a certain distance $\left(\varepsilon_{\text {reg }}\right)$ (Fig. 3b). The ICP algorithm minimizes these distances leading to an average error of $0.05 \mathrm{~cm}\left(\mu_{\mathrm{reg}}\right)$ with a standard deviation of $2.0 \mathrm{~cm}\left(\sigma_{\mathrm{reg}}\right)$ for the co-registration of individual scans of the same epoch. This standard deviation includes instrumental measurement errors $\left(\sigma_{p t}\right)$ and increases with the point spacing $\delta$. The co-registration standard deviation of sequential datasets $\left(\sigma_{\mathrm{seq}}=2.7 \mathrm{~cm}\right)$ is higher than for individual scans $\left(\sigma_{\text {reg }}\right)$, mainly because the co-registration of sequential datasets is performed on assembled point clouds and thus also includes $\sigma_{\text {reg. }}$.

The georeferencing on the ALS point cloud leads to an 
absolute positioning error of $0.55 \mathrm{~cm}$ with a standard deviation of $14.1 \mathrm{~cm}\left(\sigma_{g r}\right)$. This standard deviation is principally caused by the higher point spacing and lower point accuracy of the ALS dataset. Since the sequential point clouds are directly co-registered, the georeferencing error $\left(\sigma_{g r}\right)$ must not be included in the co-registration error of sequential TLS datasets. The final standard deviation on the co-registration of sequential TLS point clouds is $1 \sigma_{\mathrm{seq}}=2.7 \mathrm{~cm}$, including instrumental errors $\left(1 \sigma_{p t}\right)$.

Taking into account the high point density of entire TLS point clouds, i.e. by interpolated surfaces or by filtering techniques, errors are significantly lower than on single points due to the law of large numbers (Lindenbergh and Pfeifer, 2005; Abellán et al., 2009). Using a $5 \times 5$ nearest neighbour averaging, Abellán et al. (2009) have shown a reduction of the standard deviation on point measurements $\left(1 \sigma_{p t}\right)$ by a factor of 5 to 6 . The roto-translation matrix technique presented in this study also takes advantage of the high point density of the TLS datasets.

\subsection{Displacement characterization and quantification}

\subsubsection{Shortest distance comparison}

The shortest distances (SDs) between two point clouds are very useful for deformation measurements, since they allow to detect vertical, horizontal and oblique differences, and not only altitude changes, like on multi-temporal DEMs (Bitelli et al., 2004). Positive SDs signify that the points in the data point cloud are situated above or in front of the reference point cloud. In landslide studies, positive SDs can be interpreted as advances of a sliding mass or as material accumulation on debris slopes. Negative SDs mean that the data point cloud is behind or below the reference dataset and are related to vertical settlement, subsidence or erosion and rockfalls. Looking at the spatial pattern of these positive and negative differences makes it possible to delimit compartments with different displacement directions and/or velocities, and finally to propose a mechanism of deformation (Oppikofer et al., 2008b).

The differences between two sequential point clouds are computed as SDs in PolyWorks. For each point $\mathrm{i}$ of the data point cloud $\left[\mathrm{X}_{\mathrm{i} \text {.data }}, \mathrm{Y}_{\mathrm{i} \text {.data }}, \mathrm{Z}_{\mathrm{i} \text {.data }}\right]^{T}$ the $\mathrm{SD}$ algorithm searches its nearest neighbour $\mathrm{j}$ in the reference point cloud $\left[\mathrm{X}_{\mathrm{j} . \mathrm{ref}}, \mathrm{Y}_{\mathrm{j} . \mathrm{ref}}, \mathrm{Z}_{\mathrm{j} . \mathrm{ref}}\right]^{T}$ and computes the SD vector, $\boldsymbol{v}_{i}$, between both points (Eq. 1).

$\boldsymbol{v}_{i}=\left(\begin{array}{c}\Delta X_{i} \\ \Delta Y_{i} \\ \Delta Z_{i}\end{array}\right)=\left(\begin{array}{c}X_{\text {i.ref }} \\ Y_{\text {i.ref }} \\ Z_{\mathrm{i} . \text { ref }}\end{array}\right)-\left(\begin{array}{c}X_{\mathrm{j} . \text { data }} \\ Y_{\text {j.data }} \\ Z_{\mathrm{j} \text {.data }}\end{array}\right)$

Consequently the SD algorithm yields not only the Euclidian distance, $\left|\boldsymbol{v}_{i}\right|$, between closest points in sequential TLS datasets, but also the 3-D orientation of the SD vector, $\boldsymbol{v}_{i}$. As the SD computation is based on the same ICP algorithm as the co-registration procedure, the error associated to SD comparisons (SDC) corresponds to the co-registration standard deviation of sequential TLS datasets $\left(1 \sigma_{\mathrm{seq}}=2.7 \mathrm{~cm}\right)$. SDs larger than $2.7 \mathrm{~cm}$ are thus significant.

\subsubsection{Displacements vectors}

The displacement of a landslide or of individual parts in a landslide can be described by a translation, a rotation or a combination of both. A simple method to quantify the displacement velocity and direction (displacement vector) of an object is to select corresponding points on view-shaded representations of both point clouds, as described in Oppikofer et al. (2008b). Summits of blocks or small spurs and intersections or end points of discontinuity traces form good point pairs. These displacement vectors provide essential information for the modelling of landslides and the prediction of rockfall events. However the reported errors on the displacement vector (length: $1 \sigma_{\text {length }}=10 \mathrm{~cm}$; orientation: $1 \sigma_{\text {orientation }}=2-3^{\circ}$; data from Oppikofer et al., $2008 \mathrm{~b}$ for displacements of several $\mathrm{dm}$ to $\mathrm{m}$ ) are too high for the assessment of small, centimetric displacements at the Åknes rockslide. These large errors are due to the point spacing of the TLS datasets (usually between 5 and $20 \mathrm{~cm}$ in landslide displacement studies), the difficulty to identify exactly the same point on different datasets, the measurement and coregistration errors, and neglecting the effect of rotation in the movement analysis.

\subsubsection{Roto-translation matrix technique}

In order to assess small displacements, a roto-translation matrix technique based on Montserrat and Crosetto (2008) has been developed for this study. It takes into account both translation and rotation of individual parts of the rockslide (compartments), all the data points and not only point pairs, and uses thus one of the main advantages of TLS, i.e. the high point density.

Therefore, the points on each compartment are selected on the initial state scan (s) and triangulated according to a plane normal to the scanner's view direction. This triangulated model is then aligned on the final state scan (s) using the ICP algorithm implemented in PolyWorks. This affine, rigid-body transformation can be expressed by a $4 \times 4$ matrix (Stephens, 2000; Lichti et al., 2002; Monserrat and Crosetto, 2008). This roto-translation expresses the real rotation of a block around the origin of the coordinate system followed by a translation, to the final position. This translation is different from the true translation and has no significance in terms of rockslide displacements (Fig. $4 \mathrm{~b}$ ). The total transformation is better described by the translation of the centre point from its initial to its final state (Fig. 4a) followed by the real rotation of the block around its centre point (Fig. 4 and Appendix A). Frequently rotations are expressed by rotation angles around the $X-, Y$ - and $Z$-axis (Euler angles) (Monserrat and Crosetto, 2008). To facilitate the interpretation of the 


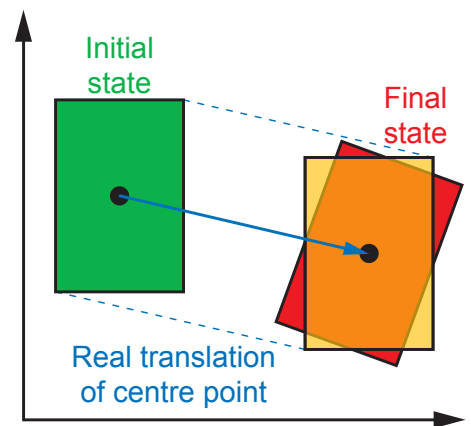

a) Translation

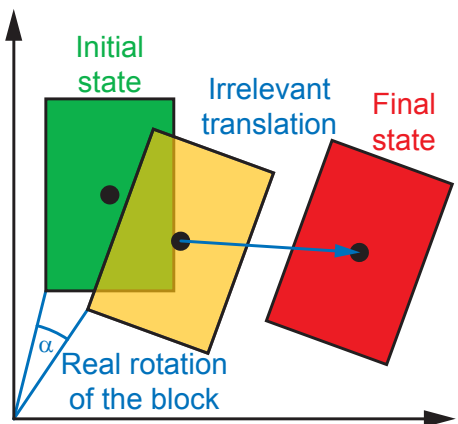

b) Roto-translation

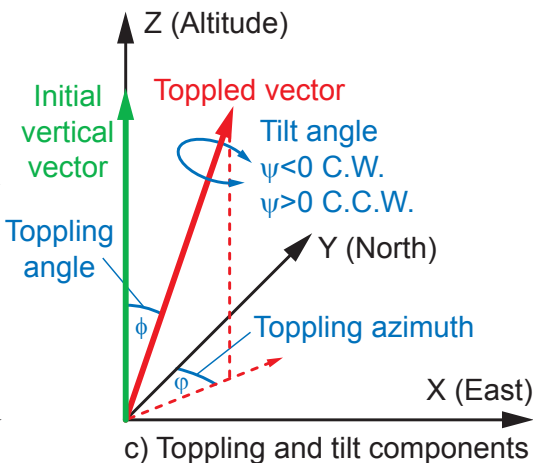

c) Toppling and tilt components

Fig. 4. 2-D representation of the alignment of a block from an initial to a final state: (a) the alignment by translation alone gives the real translation of the centre point of the block, but lacks information on eventual rotational components; (b) the roto-translation provides the best superposition and the real rotation of the block, but the translation is not meaningful in terms of displacement; (c) scheme of the rotational components in the 3-D displacement of a block. The rotation is described by the toppling azimuth and angle of an initially vertical vector and the tilt rotation around the toppled vector. Note: due to the application of the right-hand-rule, negative and positive tilt angles stand for clockwise (C.W.) and counter-clockwise (C.C.W.) rotations, respectively.

rotational component for this study, the $4 \times 4$ matrix is transformed into a toppling angle, $\phi$, and toppling direction, $\phi$, of the block as well as the tilt rotation, $\psi$, of the block around the toppled axis (Fig. 4c and Appendix A).

The precision of the calculated translational and rotational displacements is estimated by performing several times (20) the procedure for the same block. The accuracy of the magnitudes of the translational and rotational components can be estimated by applying the roto-translation matrix technique on stable parts of the slope, i.e. the main scarp (Oppikofer and Jaboyedoff, in preparation, 2009). For this assessment the TLS point cloud of the main scarp was divided into eight parts of approximately equal size and the roto-translation matrix was computed for each individual part. The computed accuracy of the translation lengths $l$ varies between $0.41 \mathrm{~cm}$ and $1.82 \mathrm{~cm}$ with a mean value of $1.10 \mathrm{~cm}\left(\sigma_{l}\right)$. The average accuracies of the toppling, $\sigma_{\phi}$, and tilt angles, $\sigma_{\Psi}$, equal $0.0141^{\circ}$ (minimum: $0.0030^{\circ}$; maximum: $0.0244^{\circ}$ ) and $0.0071^{\circ}$ (minimum: $0.0029^{\circ}$; maximum: $0.0144^{\circ}$ ), respectively (Table 1).

The accuracy of the computed translation directions (trend and plunge) depends on the displacement length and on the angle $\alpha$ between the TLS scan direction and the displacement direction (Oppikofer and Jaboyedoff, in preparation, 2009) (Fig. 5a). To assess the accuracy of the translation direction, the accuracy of the centre point coordinates must be determined. Therefore, for each point in the main scarp the SDs between sequential point clouds were computed and the three components of the SD vectors, $\boldsymbol{v}_{i}$, were analyzed statistically (Oppikofer and Jaboyedoff, in preparation, 2009). The histograms of the three components can be fitted by Gaussian distributions. The standard deviation on the range measured in the direction of the scanner's line-of-sight equals $1.61 \mathrm{~cm}$. This value is comparable to the instrumental accuracy de- termined on man-made planar structures, which are also approximately parallel to the scanner's line-of-sight. The standard deviations on the horizontal and vertical position (perpendicular to the line-of-sight) are identical with a value of $0.88 \mathrm{~cm}$. These standard deviations are used to create an error ellipsoid on the coordinates of the centre point (Fig. 5a). The major axis of the ellipsoid is parallel to the TLS scan direction. In function of $\alpha$, the minimum detectable displacement ranges from $0.88 \mathrm{~cm}\left(\alpha=90^{\circ}\right)$ to $1.61 \mathrm{~cm}\left(\alpha=0^{\circ}\right)$. Figure $5 \mathrm{~b}$ shows the decreasing errors on the computed trend and plunge angles with increasing displacements.

Similarly, the accuracy of the toppling azimuth, $\Delta \varphi$, depends on the quantity of rotational displacement given by the toppling angle, $\phi$. Using the average accuracy of the toppling angle $\left(\sigma_{\phi}=0.0141^{\circ}\right)$ the accuracy of the toppling azimuth can be calculated (Eq. 2) (Fig. 5c).

$\Delta \varphi=\arcsin \left(\frac{\phi}{\sigma_{\phi}}\right)$

For the computed centimetric displacements on the Åknes rockslide, the mean accuracy of the translation directions equals $9.1^{\circ}$ (minimum: $4.7^{\circ}$; maximum: $13.5^{\circ}$ ) and $5.5^{\circ}$ (minimum: $2.5^{\circ}$; maximum: $6.8^{\circ}$ ) for comparisons with a time span of one and two years, respectively (Fig. 5b). The average accuracy of the toppling azimuth is $26.2^{\circ}$ (minimum: $1.4^{\circ}$; maximum: $46.6^{\circ}$ ) and $19.2^{\circ}$ (minimum: $1.0^{\circ}$; maximum: $58.0^{\circ}$ ) for measurements with one and two years interval, respectively (Fig. 5c). The high errors on the toppling azimuth are due to the small toppling angles. Nevertheless, on compartments with significant toppling angles the computed directions are meaningful. For comparable displacement lengths, the roto-translation technique provides a much better accuracy on the displacement length and direction than the point pair method described above (Oppikofer and Jaboyedoff, in preparation, 2009). 

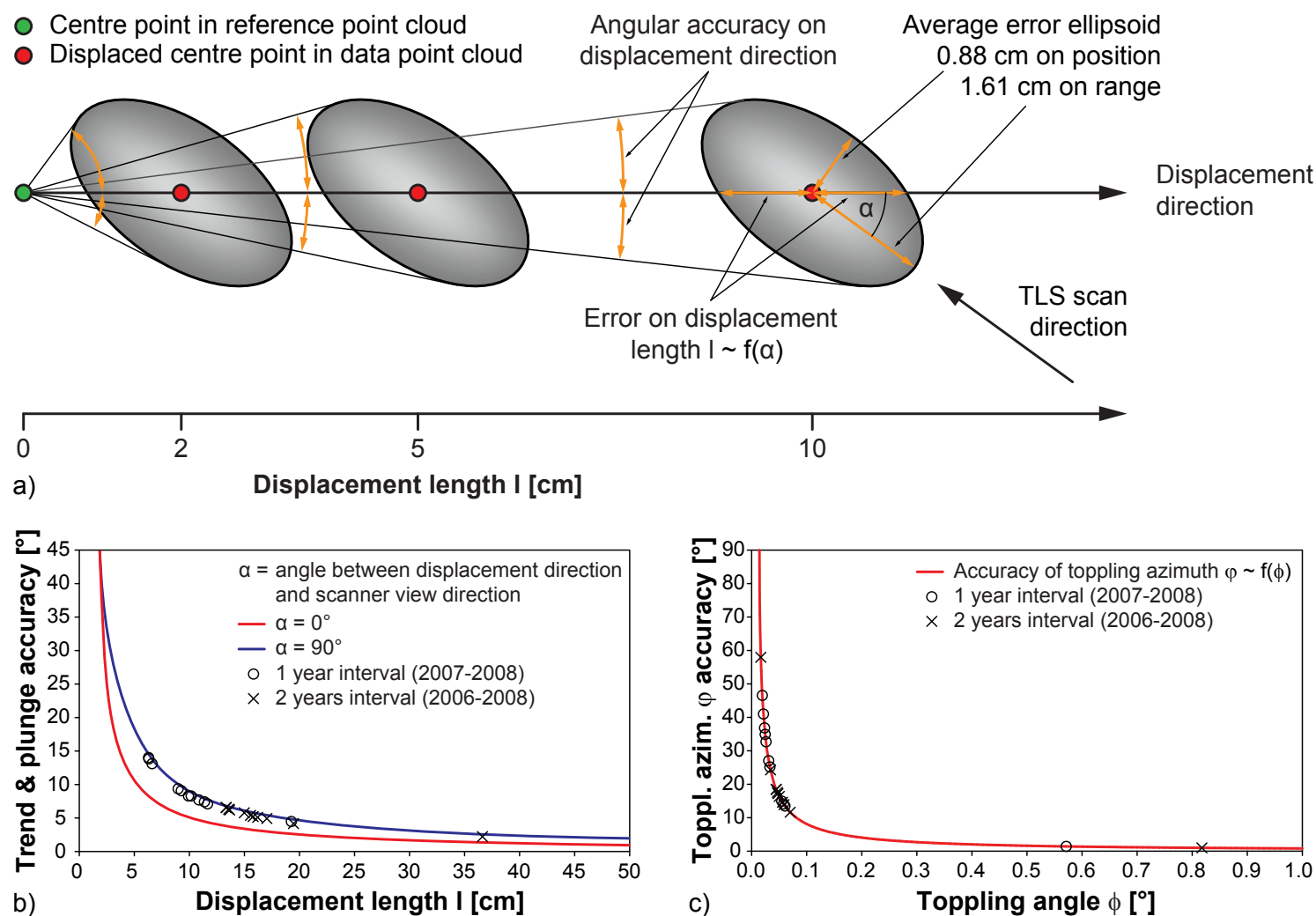

Fig. 5. Error assessment of the translation and toppling directions computed by the roto-translation matrix technique: (a) illustration explaining the decreasing error on the computed displacement direction (trend and plunge) with increasing displacement. The major axis of the error ellipsoid representing errors on the range and position measurements is parallel to the TLS scan direction. The average errors on the displacement direction and on the displacement length $l$ depend on the angle between the scanner's line-of-sight and the displacement direction $\alpha$; (b) accuracy of the computed trend and plunge angles of the displacement vector depending on $l$ and $\alpha$. The values for the compartments on the fast-moving ridge of the Åknes rockslide are shown; (c) same as in (b) but for the accuracy of the computed toppling azimuth $\phi$ depending on the toppling angle $\phi$.

Table 1. Precision and accuracy of the roto-translation matrix displacement analysis. The standard deviations and the maximum differences relative to the mean value are computed. The accuracy of the translation direction and toppling azimuth using the roto-translation matrix technique depend essentially on the amount of displacement. The point pair technique is not sensitive to rotational movements (accuracy of the point pair technique for metric displacements from Oppikofer et al., 2008b).

\begin{tabular}{lccc}
\hline Parameter & $\begin{array}{c}\text { Precision } \\
1 \sigma \text { (max. difference) }\end{array}$ & $\begin{array}{c}\text { Accuracy } \\
1 \sigma \text { (max. difference) }\end{array}$ & $\begin{array}{c}\text { Accuracy of point pair technique } \\
\end{array}$ \\
\hline Translation length $[\mathrm{cm}]$ & $0.02(0.06)$ & $1.10(1.82)$ & 10 \\
Translation direction $\left[^{\circ}\right]$ & $0.28(0.52)$ & $*$ & $2-3$ \\
Translation plunge $\left[^{\circ}\right]$ & $0.52(1.11)$ & $*$ & $2-3$ \\
Toppling azimuth $\left[^{\circ}\right]$ & $1.80(3.30)$ & $*$ & n.d. \\
Toppling angle $\left[^{\circ}\right]$ & $0.0019(0.0031)$ & $0.0141(0.0244)$ & n.d. \\
Tilt angle $\left[{ }^{\circ}\right]$ & $0.0057(0.0076)$ & $0.0071(0.0144)$ & n.d. \\
\hline
\end{tabular}

* depend on the translation length and toppling angle (Fig. 5); n.d. = not detectable 

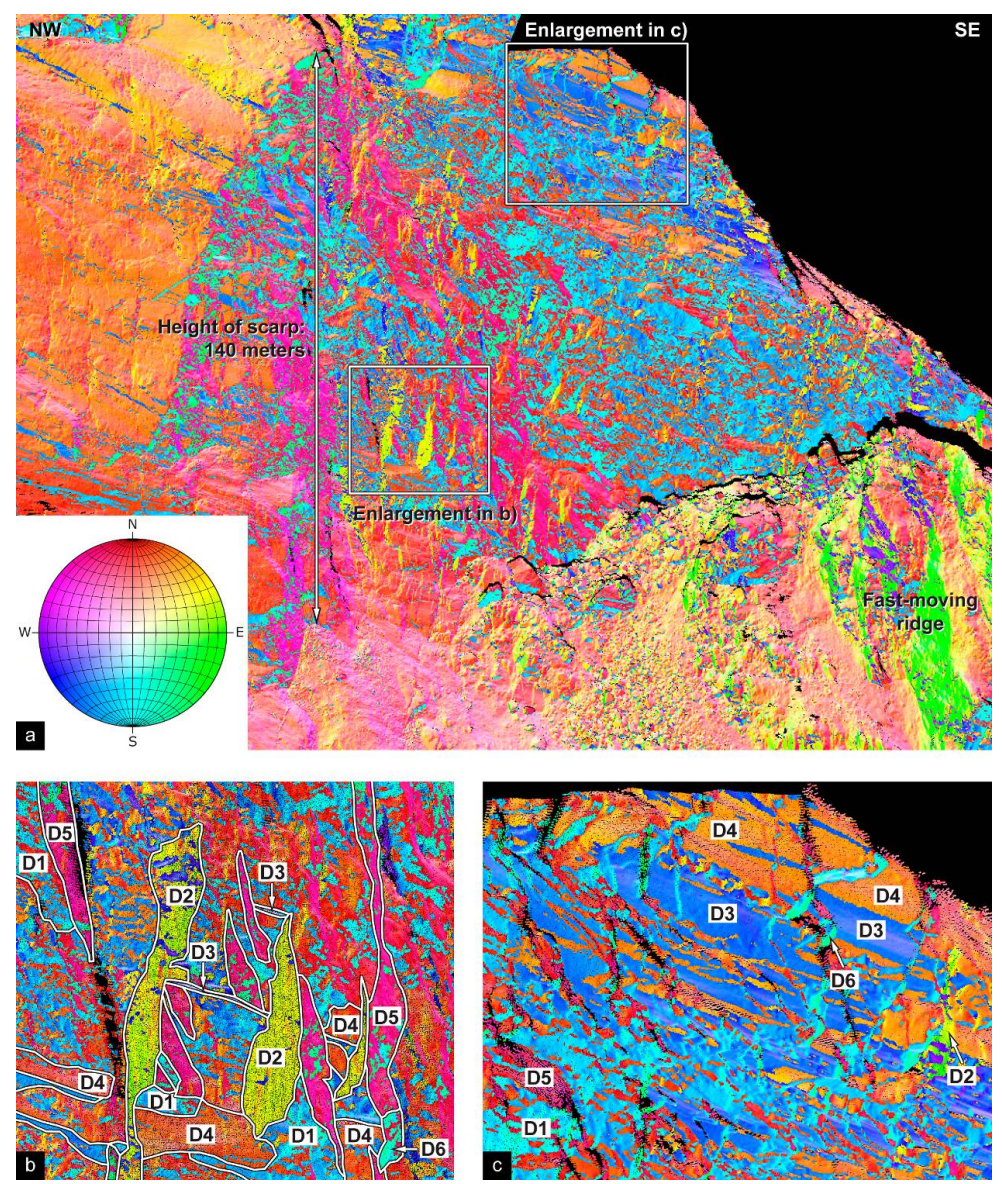

Fig. 6. (a) Coltop3D representation of the TLS point cloud of the Åknes rockslide main scarp (Inset: lower hemisphere stereonet of the Coltop3D colour representation of each spatial orientation, modified from Jaboyedoff et al., 2007); (b) enlargement showing the six discontinuity sets (see Table 2). Some colour changes, e.g. from light blue to red in D1, yellow to blue in D2 or magenta to green in D5, are due to overhanging parts in these subvertical discontinuity sets; (c) enlargement displaying the folds in the upper part of the scarp with D4 and D3 forming the normal and reverse fold limbs, respectively.
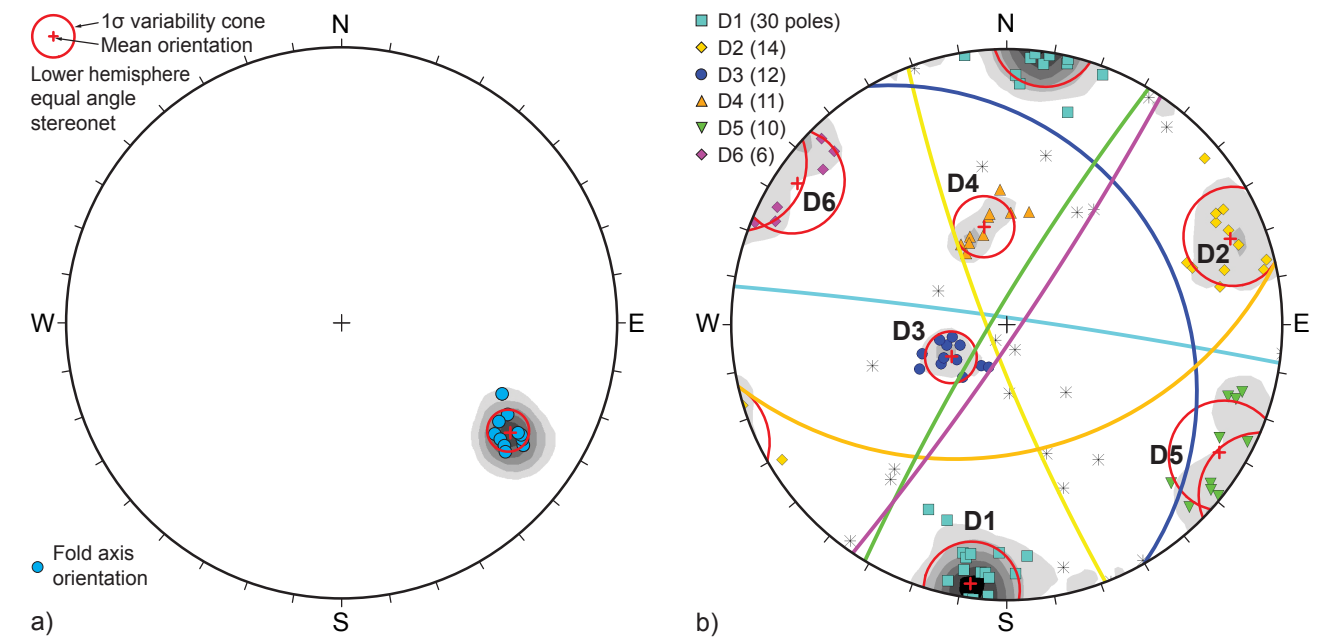

Fig. 7. Stereonet of major structural features in the Åknes rockslide main scarp obtained by fitting geometrical forms in PolyWorks: (a) the SE-plunging fold axis orientations; (b) 106 poles of discontinuities forming six discontinuity sets (D1 to D6). 
Table 2. Discontinuity sets in the main scarp of Åknes rockslide based on manual fitting of planes in PolyWorks and the selection of discontinuities based on the orientation-specific colouring in Coltop3D.

\begin{tabular}{cccc}
\hline Set & $\begin{array}{c}\text { Manual approach } \\
\text { (PolyWorks) }\end{array}$ & $\begin{array}{c}\text { Semi-automatic approach } \\
\text { (Coltop3D) }\end{array}$ & $\begin{array}{c}\text { Coltop3D colour } \\
\text { (in Fig. 6) }\end{array}$ \\
\hline D1 & $008^{\circ} / 87^{\circ} \pm 9^{\circ}$ & $014^{\circ} / 84^{\circ} \pm 10^{\circ}$ & Light blue \\
D2 & $249^{\circ} / 82^{\circ} \pm 12^{\circ}$ & $247^{\circ} / 82^{\circ} \pm 11^{\circ}$ & Yellow \\
D3 & $060^{\circ} / 26^{\circ} \pm 10^{\circ}$ & $070^{\circ} / 35^{\circ} \pm 7^{\circ}$ & Bluish white \\
D4 & $167^{\circ} / 40^{\circ} \pm 11^{\circ}$ & $186^{\circ} / 41^{\circ} \pm 10$ & Orange-red \\
D5 & $124^{\circ} / 85^{\circ} \pm 12^{\circ}$ & $149^{\circ} / 82^{\circ} \pm 11^{\circ}$ & Magenta \\
D6 & $301^{\circ} / 84^{\circ} \pm 13^{\circ}$ & $333^{\circ} / 75^{\circ} \pm 10^{\circ}$ & Green-blue \\
\hline
\end{tabular}

\subsection{Structural analysis}

Hard rock slopes are generally shaped by major discontinuity sets (Terzaghi, 1962; Selby, 1982; Jaboyedoff et al., 2004). Their orientations can thus be determined using an ALS-DEM or a TLS point cloud with the predominant orientations of the topographic surfaces corresponding to the orientation of the main fracture sets (Jaboyedoff et al., 2004, 2007, 2009).

The orientation of discontinuity sets or fold axes can be obtained by fitting simple geometric forms (planes for discontinuities, cylinders or cones for folds) through selected points in PolyWorks (manual approach). Another technique consists of computing the spatial orientation (dip direction and dip angle) of each point with respect to its neighbourhood in the software Coltop3D (Jaboyedoff et al., 2007; Metzger and Jaboyedoff, 2008) (Fig. 6). Coltop3D attributes a unique RGB colour to each spatial orientation (Fig. 6a), which permits the user to visually identify the discontinuity sets and to select areas with the same colour and consequently also the same orientation (Fig. 6b) for the computation of the average dip direction and dip angle (semiautomatic approach) (Jaboyedoff et al., 2004, 2007). In both approaches the variability of the discontinuity set orientation can be expressed by the aperture angle of the cone centred on the mean orientation of the discontinuity set and enveloping 68\% $(1 \sigma)$ of the data (Wyllie and Mah, 2004; Rocscience, 2007).

\section{Results}

\subsection{Structural analysis}

The main scarp of the Åknes landslide is approximately $200 \mathrm{~m}$ high and $300 \mathrm{~m}$ wide. Difficult access impedes structural measurements at the bottom of the scarp. Terrestrial laser scans of the scarp are therefore used for the analysis of the main structural features.

\subsubsection{Fold axis}

Several folds are visible on the main scarp (Fig. 6). Assuming a cylindrical shape for the folds allows modelling by fitting cylinders through the TLS points of the folds (Fig. 7a). The fold axes have a mean orientation of $123^{\circ} / 18^{\circ}$ (trend/plunge) with only small variability $\left(1 \sigma=5.7^{\circ}\right)$. This fold axis orientation is in agreement with the "gently ESEplunging axis" reported by Braathen et al. (2004, p. 74).

\subsubsection{Discontinuity sets}

In different parts of the Åknes main scarp and its surroundings, orientations of discontinuities were determined. With the manual approach more than 100 discontinuities were measured and attributed to one of six discontinuity sets (Fig. $7 \mathrm{~b}$ and Table 2). The discontinuity sets obtained by Coltop3D (semi-automatic approach) are very similar to those using the manual approach (Fig. 6 and Table 2). However, Coltop3D provides more detailed information by revealing overhanging walls in the steep discontinuity sets D1, D2 and D5 (Fig. 6b).

D4 is the main orientation of the gneiss foliation in the scarp area. Due to the folds, the gneiss foliation creates overhanging surfaces, which form the D3 discontinuity set in the fold hinge zones (Fig. 6c). These folds are cut by the other discontinuity sets, which are found throughout the scarp area with only slight variations in orientation. The apparent persistence of these discontinuities is illustrated by the area shaped by each discontinuity. It is highly variable with D1, D2 and D5 shaping large areas of the main scarp, while D6 in general forms only small surfaces within D5 fractures (Fig. 6b). However, the discontinuity sets D5 and D6 can be subdivided into two sets since they are observed next to each other separated by a well-defined intersection line. 


\subsection{Displacement analysis of the fast-moving ridge}

\subsubsection{Shortest distance comparison (SDC)}

On the fast-moving ridge in the uppermost part of the Åknes rockslide (Fig. 2), the SDC between the scans taken at the beginning of August and the middle of September 2006 reveals small displacements (approximately 1 to $2 \mathrm{~cm}$ ) towards the SE (Oppikofer et al., 2008a), but they are not significant given the error on point comparisons. Between 3 August 2006 and 7 August 2007 the ridge moved towards the South with a horizontal displacement of 6 to $8 \mathrm{~cm}$ and a vertical displacement of 4 to $6 \mathrm{~cm}$ (Oppikofer et al., 2008a).

The SDC of the 2006 and 2008 datasets is shown in Fig. 8. This comparison gives evidence of a southward movement of the whole ridge by 12 to $18 \mathrm{~cm}$ (orange colours at the front of the fast-moving ridge in Fig. 8) along with a downward movement by approximately $6 \mathrm{~cm}$ (light blue colours on the top of the ridge). This SDC also reveals the subsidence of the debris (up to $-24 \mathrm{~cm}$ ) in the graben, which opened between the main scarp and the fast-moving ridge (Fig. 8). In this subsidence area, two small freestanding columns with high displacements (up to $+24 \mathrm{~cm}$ ) are detected. The debris at the foot of the fast-moving ridge are also moving towards the South with displacements varying between $6 \mathrm{~cm}$ and $24 \mathrm{~cm}$ for individual blocks (yellow to red colours in the foreground of Fig. 8).

\subsubsection{Roto-translation matrix analysis}

For the detailed analysis of the displacements, the fastmoving ridge was divided into 11 compartments - labelled R1 to R10 - on the basis of the SDC and the morphology (Fig. 8). For each compartment, a mesh of the 2006 TLS scans was created and aligned first onto the 2007 point cloud and afterwards on the 2008 dataset. Using the rototranslation matrix technique, the complete 3-D movement of each compartment was calculated for each possible comparison (2006 vs. 2007, 2007 vs. 2008 and 2006 vs. 2008) (Table 3). Figure 9 shows the translation vectors and toppling directions and angles for the 2-year period between $\mathrm{Au}$ gust 2006 and August 2008. All of the measured translation vector lengths and most toppling angles are significant since they are greater than the accuracy of the roto-translation matrix technique (Table 1).

The compartment $\mathrm{R} 1$ is a detached column sliding and toppling towards the graben in the North (translation length of $36.4 \mathrm{~cm}$ and toppling angle of $0.818^{\circ}$ in two years) and shows a clearly different displacement pattern than the other compartments of the ridge. R1 was therefore excluded from the displacement analysis of the fast-moving ridge.

The translation vectors of the compartments $\mathrm{R} 2$ to $\mathrm{R} 10$ are quite homogenous in length and direction. The different compartments move towards the SSW to SW (between $196^{\circ} \mathrm{N}$ and $227^{\circ} \mathrm{N}$ ) and the length of the translation vectors
Table 3. Displacement analysis of 11 compartments on the fastmoving ridge: the length and orientation of the translation vector, the toppling direction and angle, as well as the tilt angle are derived from the affine transformation matrix between the initial state and the final state for the comparisons 2006 to 2007, 2007 to 2008 and 2006 to 2008 . Values in brackets are smaller than the accuracy of the technique and are therefore not significant.

\begin{tabular}{|c|c|c|c|c|c|c|c|}
\hline \multirow[b]{2}{*}{ Compartment } & \multirow[b]{2}{*}{ Period } & \multicolumn{3}{|c|}{ Centre point translation } & \multicolumn{2}{|c|}{ Toppling } & \multirow{2}{*}{$\begin{array}{c}\text { Tilt } \\
\text { Angle } \\
{\left[^{\circ}\right]}\end{array}$} \\
\hline & & $\begin{array}{l}\text { Length } \\
{[\mathrm{cm}]}\end{array}$ & $\begin{array}{c}\text { Trend } \\
{\left[{ }^{\circ}\right]}\end{array}$ & $\begin{array}{c}\text { Plunge } \\
{\left[{ }^{\circ}\right]}\end{array}$ & $\begin{array}{c}\text { Azimuth } \\
{\left[{ }^{\circ}\right]}\end{array}$ & $\begin{array}{c}\text { Angle } \\
{\left[{ }^{\circ}\right]}\end{array}$ & \\
\hline \multirow{3}{*}{$\mathrm{R} 1$} & $2006-2007$ & 17.7 & 312.9 & 58.7 & 42.3 & 0.296 & -0.016 \\
\hline & 2007-2008 & 19.1 & 289.4 & 56.5 & 1.2 & 0.571 & 0.017 \\
\hline & $2006-2008$ & 36.4 & 299.9 & 57.8 & 14.9 & 0.818 & 0.033 \\
\hline \multirow{3}{*}{$\mathrm{R} 2$} & $2006-2007$ & 7.9 & 205.3 & 60.2 & 342.3 & 0.036 & -0.019 \\
\hline & $2007-2008$ & 11.5 & 229.5 & 54.8 & 329.5 & 0.024 & 0.025 \\
\hline & $2006-2008$ & 19.3 & 220.2 & 57.5 & 337.2 & 0.059 & 0.044 \\
\hline \multirow{3}{*}{ R3 } & 2006-2007 & 6.0 & 184.7 & 54.0 & 43.1 & 0.020 & -0.021 \\
\hline & $2007-2008$ & 9.7 & 210.2 & 46.9 & 348.8 & 0.033 & 0.027 \\
\hline & $2006-2008$ & 15.6 & 201.5 & 50.0 & 8.7 & 0.048 & 0.048 \\
\hline \multirow{3}{*}{$\mathrm{R} 3 \mathrm{a}$} & 2006-2007 & 6.2 & 190.6 & 48.6 & 187.1 & 0.073 & -0.019 \\
\hline & $2007-2008$ & 10.0 & 205.0 & 48.0 & 357.3 & 0.061 & 0.011 \\
\hline & 2006-2008 & 16.0 & 199.7 & 48.1 & 225.9 & 0.017 & 0.030 \\
\hline \multirow{3}{*}{ R4 } & 2006-2007 & 7.1 & 217.4 & 61.0 & 21.5 & 0.026 & -0.019 \\
\hline & $2007-2008$ & 6.4 & 232.6 & 56.3 & 0.4 & 0.031 & 0.026 \\
\hline & $2006-2008$ & 13.5 & 225.1 & 59.0 & 10.0 & 0.056 & 0.045 \\
\hline \multirow{3}{*}{ R5 } & 2006-2007 & 4.8 & 203.2 & 60.8 & 350.9 & 0.026 & 0.027 \\
\hline & $2007-2008$ & 10.7 & 210.5 & 45.4 & 306.8 & 0.022 & 0.046 \\
\hline & 2006-2008 & 15.4 & 208.8 & 50.1 & 331.2 & 0.044 & 0.019 \\
\hline \multirow{3}{*}{ R6 } & 2006-2007 & 6.0 & 178.6 & 37.9 & 340.6 & $(0.013)$ & 0.016 \\
\hline & $2007-2008$ & 11.2 & 209.4 & 41.8 & 4.7 & 0.058 & 0.049 \\
\hline & 2006-2008 & 16.9 & 198.4 & 41.5 & 0.4 & 0.070 & 0.034 \\
\hline \multirow{3}{*}{ R7 } & 2006-2007 & 7.5 & 159.4 & 40.8 & 16.4 & 0.023 & $(-0.001)$ \\
\hline & $2007-2008$ & 8.8 & 230.4 & 45.5 & 55.6 & 0.026 & 0.016 \\
\hline & $2006-2008$ & 14.8 & 196.4 & 49.2 & 37.1 & 0.047 & 0.017 \\
\hline \multirow{3}{*}{ R8 } & 2006-2007 & 7.5 & 205.7 & 60.9 & 333.5 & 0.043 & $(-0.004)$ \\
\hline & $2007-2008$ & 6.1 & 249.5 & 55.4 & 70.9 & 0.019 & 0.023 \\
\hline & $2006-2008$ & 13.4 & 226.7 & 60.3 & 359.1 & 0.045 & 0.027 \\
\hline \multirow{3}{*}{ R9 } & 2006-2007 & 8.9 & 177.1 & 57.1 & 3.6 & 0.026 & $(-0.001)$ \\
\hline & $2007-2008$ & 6.1 & 280.2 & 46.1 & 346.3 & 0.025 & 0.030 \\
\hline & $2006-2008$ & 13.1 & 224.0 & 64.5 & 355.2 & 0.050 & 0.031 \\
\hline \multirow{3}{*}{ R10 } & 2006-2007 & 5.0 & 158.8 & 55.5 & 190.8 & 0.021 & -0.026 \\
\hline & $2007-2008$ & 9.1 & 211.3 & 33.1 & 1.3 & 0.055 & $(-0.007)$ \\
\hline & $2006-2008$ & 13.2 & 197.8 & 43.6 & 355.6 & 0.034 & 0.019 \\
\hline \multirow{3}{*}{$\begin{array}{l}\text { Mean } \\
\text { (without R1) }\end{array}$} & 2006-2007 & 6.9 & 199.2 & 64.8 & 28.9 & 0.034 & $(-0.008)$ \\
\hline & $2007-2008$ & 8.7 & 221.6 & 48.6 & 0.3 & 0.031 & 0.025 \\
\hline & $2006-2008$ & 14.9 & 207.8 & 52.7 & 357.5 & 0.042 & 0.032 \\
\hline \multirow{3}{*}{$\begin{array}{l}\text { Weighted } \\
\text { mean }\end{array}$} & 2006-2007 & 6.2 & 179.3 & 56.7 & 9.8 & $(0.010)$ & $(-0.004)$ \\
\hline & $2007-2008$ & 8.7 & 220.7 & 45.6 & 358.5 & 0.038 & 0.021 \\
\hline & 2006-2008 & 14.5 & 206.1 & 51.9 & 0.9 & 0.048 & 0.024 \\
\hline
\end{tabular}

varies between 13.1 to $19.3 \mathrm{~cm}$ between 2006 and 2008. The translation direction of the northern compartments is more to the $\mathrm{SW}$ and steeper plunging (between $57^{\circ}$ and $64^{\circ}$ for $\mathrm{R} 2$, $\mathrm{R} 4, \mathrm{R} 8$ and R9) than the southern compartments (between $41^{\circ}$ and $50^{\circ}$ for R3, R3a, R5, R6, R7 and R10). This higher subsidence can be explained by the opening of the graben structure between the back scarp and the ridge.

The global displacement of the fast-moving ridge can be described by the average of the displacement vectors 


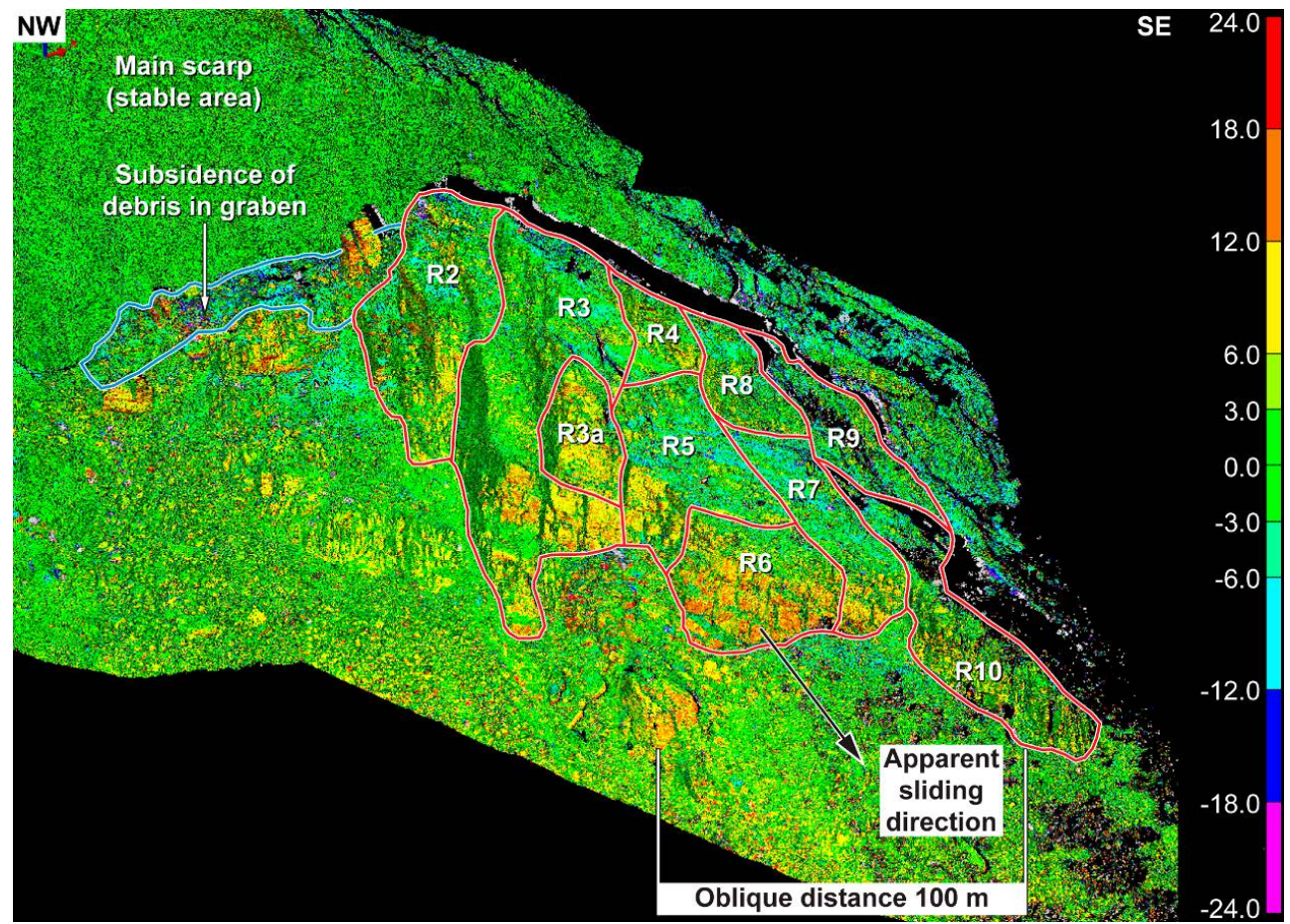

Fig. 8. Shortest distance comparison of the TLS point clouds from 3 August 2006 and 24 August 2008. Positive differences up to $+24 \mathrm{~cm}$ are shown in yellow to red colours and negative differences up to $-24 \mathrm{~cm}$ in light to dark blue colours. The 10 compartments on the fast-moving ridge (R1 is hidden by R2) used for the detailed displacement analysis using the roto-translation matrix technique are outlined. Debris are subsiding in a graben opened between the main scarp and the fast-moving ridge. In the foreground of the comparison image, the debris at the foot of the ridge are also moving with variable displacements ranging from 6 to $24 \mathrm{~cm}$ in two years.
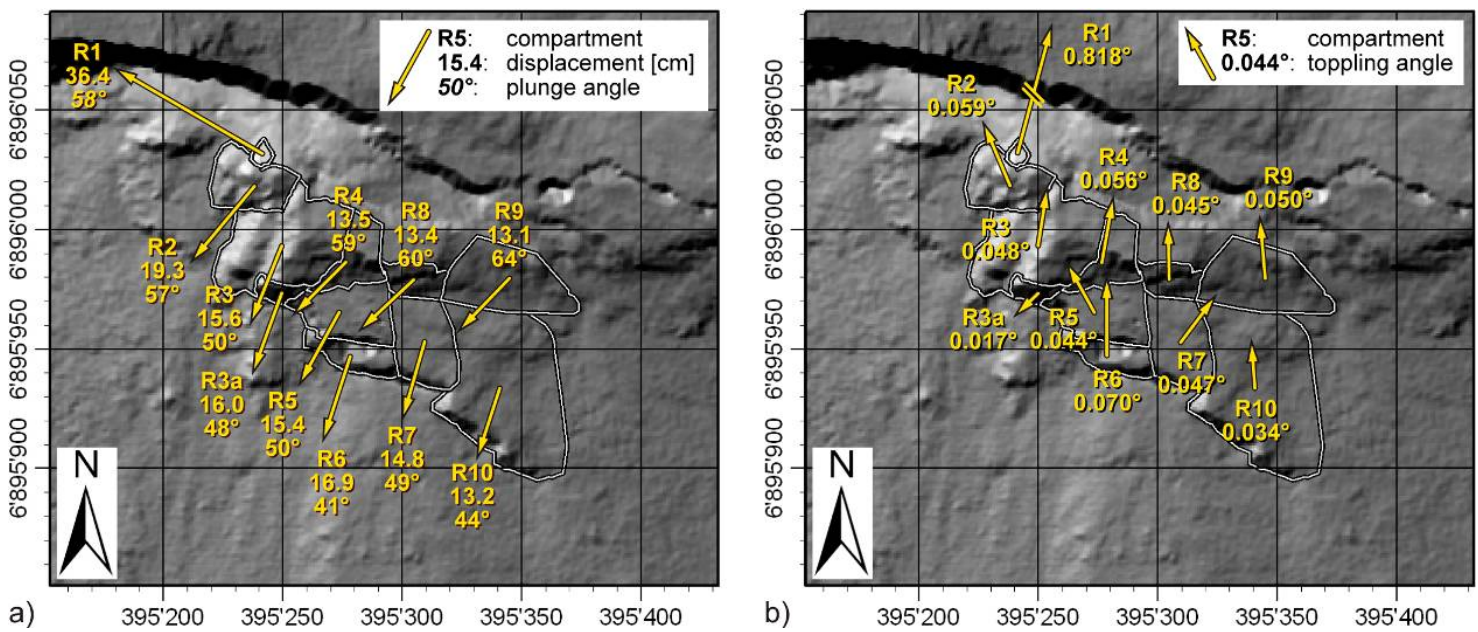

Fig. 9. Map of the 11 compartments on the ridge: (a) the arrows indicate the direction and amplitude of the displacement vector between August 2006 and August 2008; (b) shows the toppling direction (indicated by the azimuth of the arrow) and the toppling angle (indicated by the length of the arrow and the number) from August 2006 to August 2008. 
$\left(208^{\circ} / 53^{\circ}, 14.9 \mathrm{~cm}\right.$ in two years) or the mean value weighted by the horizontal surface of each compartment $\left(206^{\circ} / 52^{\circ}\right.$, $14.5 \mathrm{~cm}$ between 2006 and 2008). These calculated displacements are similar to the shortest differences visible in the comparison image (Fig. 8).

Except for R3a that is toppling towards the SW, the compartments topple towards the North (ranging from $331^{\circ} \mathrm{N}$ to $037^{\circ} \mathrm{N}$; weighted mean toppling direction: $001^{\circ} \mathrm{N}$ ). Toppling angles are low $\left(<0.1^{\circ}\right)$ with a weighted mean angle of $0.048^{\circ}$. Nonetheless, a toppling by $0.048^{\circ}$ of a $50 \mathrm{~m}$ high compartment, as found on the ridge in Åknes rockslide, leads to a displacement of $4.2 \mathrm{~cm}$ at its top. This toppling component is in good agreement with the different displacement patterns detected by the SDC (Fig. 8). The northward toppling combined to southward sliding leads to higher SD at the foot of the fast-moving ridge ( $>12 \mathrm{~cm}$, orange to red colours at the foot of R3, R5 and R6 in Fig. 8), smaller SD at the top of the cliff $(<12 \mathrm{~cm}$, green to yellow colours in the upper part of the compartments in Fig. 8) and higher negative SD on the top of the ridge $(<-6 \mathrm{~cm}$, light blue colours on the top of the ridge compartments in Fig. 8). The tilt angles, i.e. the rotation of the compartment around the toppled normal axis, are low $\left(<0.05^{\circ}\right)$ and have little significance in terms of sliding or toppling.

Between the detailed displacements analyses for 2006 vs. 2007 and 2007 vs. 2008 most of the compartments show a coherent movement pattern with only small differences in translation direction and amplitude as well as in toppling direction and toppling angle (Table 3). However, the differences in the translation direction (trend and plunge) increase with increasing distance from the main scarp (compartments $\mathrm{R} 7, \mathrm{R} 8, \mathrm{R} 9$ and R10). These variations are probably not caused by a change in the displacement direction of the ridge, but can be partly explained by the relatively low accuracy of the translation directions for centimetric displacements (Fig. 5). In the southern part of the ridge, lower point densities (especially for R9 and R10, see Fig. 8) and increasing co-registration errors with increasing distance between the stable reference points and these compartments can explain the important discrepancies in the displacement directions. The displacement analysis between 2006 and 2008 provides the most reliable results possible, since the slope movements are higher than for the yearly comparisons and consequently the accuracy of the translation and toppling directions is significantly better (Fig. 5).

\section{Interpretation and instability mechanism}

For the ridge in the uppermost part of the Åknes rockslide, Braathen et al. (2004) stated that "transport is parallel to the surface, which dips $30-40^{\circ}$ to the South" (p. 74) and the available point measurements on the fast-moving ridge show a displacement towards the $\mathrm{S}$ to $\mathrm{SW}$ by 5 to $9 \mathrm{~cm} /$ year (Fig. 1c, Table 4). For the same point on compartment R3, the permanent GPS and laser distacemeters show sig- nificant differences in displacement velocity (between 6.4 and $8.1 \mathrm{~cm}$ ) and displacement direction (between $199^{\circ} \mathrm{N}$ and $211^{\circ} \mathrm{N}$ for the trend and $31^{\circ}$ to $64^{\circ}$ for the plunge). The translation components of compartments R3 and R9 determined by TLS are similar to the point-based measurements within the given accuracy limits (Table 4).

The general displacement direction of the fast-moving ridge is confirmed by the TLS measurements (weighted mean: $207^{\circ} \mathrm{N}$ ) and is comparable to the dip direction of the gneiss foliation in the normal limbs of the isoclinal folds (D4: $186^{\circ} / 41^{\circ}$ (Coltop3D data), see Table 2). In fact, the gneiss foliation likely forms the basal sliding surface of the Åknes rockslide (Fig. 10) (Henderson et al., 2006; Kveldsvik et al., 2006; Ganerød et al., 2008). Undulations of the gneiss foliation create changes in both dip direction (between $155^{\circ} \mathrm{N}$ and $205^{\circ} \mathrm{N}$ ) and dip angle (between $27^{\circ}$ and $45^{\circ}$ ) (data from Derron et al. (2005), Kveldsvik et al. (2006), Ganerød et al. (2008) and this study). The obtained plunge of the translation vector is similar to the point-based measurements (Table 4$)$ and significantly higher $\left(52^{\circ}\right)$ than the average slope angle $\left(37^{\circ}\right)$ in the upper part of the Åknes rockslide and the values for the foliation dip angle reported in previous studies $\left(27^{\circ}\right.$ to $45^{\circ} ; 41^{\circ}$ in this study). This more important downward movement of the uppermost part of the Åknes rockslide is probably made possible by a complex, stepped sliding surface (Fig. 10). The planar sliding along the foliation opens voids along the stepped surface. These voids get filled by the vertical settlement of the overlying fast-moving ridge explaining its high downward displacements (Fig. 10). These vertical movements are likely associated to brittle fracturing. A microseismic monitoring network operated at the Åknes rockslide since 2005 shows increased seismic activity during acceleration phases of the rockslide after heavy rainfalls or snowmelt (Roth and Blikra, 2009). The assumed stepped sliding surface is created by the preferential rupture along the hinges of the isoclinal folds (Jaboyedoff et al., submitted, 2009), as observed in the main scarp of the Åknes rockslide (Figs. 2 and 6), and along the gneiss foliation. A similar stepped surface of an ancient rockslide is exposed $2.5 \mathrm{~km}$ south of the Åknes rockslide (Oppikofer and Jaboyedoff, 2007; Oppikofer et al., in preparation, 2009).

The planar sliding parallel to the gneiss foliation also opened a graben structure between the main scarp and the fast-moving ridge (Fig. 10). This graben is partially filled with debris, but allows blocks that are delimited by discontinuity sets D1 (rear), D3 (basal), and D5 or D6 (lateral) to topple towards the graben. In addition, the measured rotational movements of the ridge towards the North can also be explained by rock slumping. The compartment Ridge 3a is delimited by discontinuity sets D1 (rear), D4 (basal), and D5 (lateral) and is able to topple-slide towards the South (Fig. 10), which is supported by the measured toppling direction and toppling angle. Finally, it is the planar sliding mechanism that leads to the apparent rotational movements of the uppermost part. 
Table 4. Comparison of the translational displacements of compartments R3 and R9 measured by different point-based instruments, i.e. permanent GPS and laser distancemeters (data provided by the Åknes/Tafjord project), and TLS.

\begin{tabular}{llccccc}
\hline Compartment & Instrument & Period (days) & $\begin{array}{c}\text { Displacement } \\
{[\mathrm{cm}]}\end{array}$ & $\begin{array}{c}\text { Velocity } \\
{[\mathrm{cm} / \text { year }]}\end{array}$ & $\begin{array}{c}\text { Trend } \\
{\left[{ }^{\circ}\right]}\end{array}$ & $\begin{array}{c}\text { Plunge } \\
{\left[{ }^{\circ}\right]}\end{array}$ \\
\hline \multirow{4}{*}{ R3 } & GPS ${ }^{*}$ & $26.03 .07-28.07 .08(490)$ & 10.9 & 8.1 & 198.7 & 58.7 \\
& GPS & $07.08 .07-24.08 .08(383)$ & 7.4 & 7.1 & 202.5 & 63.7 \\
& Laser ${ }^{+}$ & $07.08 .07-24.08 .08(383)$ & 6.7 & 6.4 & 211.0 & 30.8 \\
& TLS & $07.08 .07-24.08 .08(383)$ & 9.7 & 9.2 & 210.2 & 46.9 \\
\hline \multirow{2}{*}{ R9 } & Laser ${ }^{+}$ & $07.08 .07-24.08 .08(383)$ & 7.8 & 7.5 & 160.3 & 44.1 \\
& TLS & $07.08 .07-24.08 .08(383)$ & 6.1 & 5.8 & 280.2 & 46.1 \\
\hline
\end{tabular}

*data from Nordvik and Nyrnes (2009), ${ }^{+}$fixed line-of-sight (trend/plunge) for the laser distancemeters.

\section{Conclusions and perspectives}

The terrestrial laser scanner survey of the upper part of the Åknes rockslide shows the potential of this new method. TLS provides high resolution point clouds of the topography, which complement the DEM generated from aerial laser scanning that often lack precise information in the steep cliffs. TLS data on inaccessible cliffs, such as the main scarp of the Ånnes rockslide, enable a detailed analysis of the main structural features including major discontinuity sets and fold axes. New software tools, like Coltop3D, improve the ability to extract the relevant structures from point clouds.

More important for landslide hazard assessment and landslide monitoring is the potential of TLS to detect global slope movements over the whole landslide area and not just at single monitoring points. In contrast to many other monitoring techniques, TLS provides information not only on the total amount of displacement in the line-of-sight, but also on the type of movement, i.e. translation and/or rotation. Comparisons of TLS point clouds of the upper part of the Åknes rockslide reveal displacements as low as a few centimetres and up to several decimetres. In contrast to other area-based monitoring techniques, the range of measurable displacements by TLS is very large leading to a wide range of potential landslide monitoring applications. TLS is also capable of providing rapid precise 3-D topographic information for quick hazard assessment in emergency situations (Jaboyedoff et al., accepted, 2009).

The improved roto-translation technique is well suited for displacement measurement and the interpretation of the movement in terms of landslide mechanism. The measured displacements are consistent with the overall movement of the Åknes rockslide. A possible rockslide mechanism model, including planar sliding as well as toppling and vertical settlement for the uppermost part of the Åknes rockslide, was established on the basis of the TLS data. This instability model still requires testing and comparison with other models based on structural and geomorphologic observations, as well as on geophysical investigations.

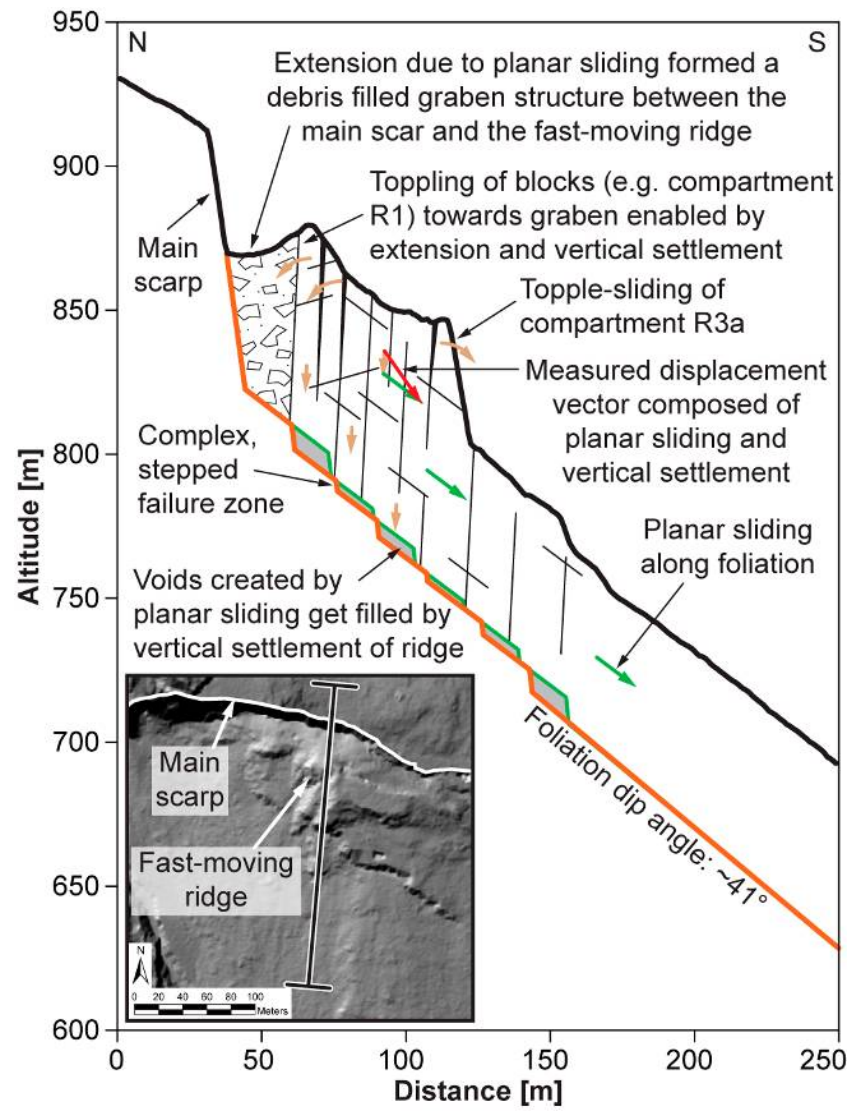

Fig. 10. Schematic profile across the upper part the Áknes rockslide (based on the ALS-DEM, (C) Åknes/Tafjord Project) explaining the measured displacement vectors by planar sliding and vertical settlement along a complex stepped basal sliding surface and the toppling at the front of the ridge and towards the graben (modified from Oppikofer et al., 2008a). The location and shape of the basal sliding surface is not exactly known and the foliation is undulating. A mean foliation dip angle of $41^{\circ}$ was chosen for this conceptual model. 


\section{Appendix A}

The $4 \times 4$ matrix associated to the affine, rigid-body transformation from the initial to the final position (Eq. A1) is composed of $3 \times 3$ terms for the rotation $\left(r_{11}\right.$ to $\left.r_{33}\right), 3$ terms for the translation $\left(t_{14}\right.$ to $\left.t_{34}\right)$ and a fourth line being generally [0,0,0,1] (Stephens, 2000; Lichti et al., 2002).

$$
\mathbf{M}_{\mathrm{tot}}=\left(\begin{array}{cccc}
r_{11} & r_{12} & r_{13} & t_{14} \\
r_{21} & r_{22} & r_{23} & t_{24} \\
r_{31} & r_{32} & r_{33} & t_{34} \\
0 & 0 & 0 & 1
\end{array}\right)
$$

The real translation, $\boldsymbol{t}$, is expressed as a vector between the block's centre point in the initial and the final state (Fig. 4a), which is obtained by multiplication of the centre point by the roto-translation matrix (Eq. A2).

$$
\boldsymbol{t}=\left(\begin{array}{c}
\Delta X \\
\Delta Y \\
\Delta Z \\
0
\end{array}\right)=\mathbf{M}_{\mathrm{tot}} \cdot\left(\begin{array}{c}
X \\
Y \\
Z \\
1
\end{array}\right)-\left(\begin{array}{l}
X \\
Y \\
Z \\
1
\end{array}\right)
$$

The total transformation equals the translation of the centre point to its final state, $\boldsymbol{t}$, followed by the rotation, $\mathbf{M}_{\mathrm{rot}}$, of the block around its centre point. The rotation component of $\mathbf{M}_{\text {rot }}$ is given by the $4 \times 4$ roto-translation matrix $\mathbf{M}_{\text {tot }}$, while the translation components are equal to 0 (Eq. A3).

$\mathbf{M}_{\mathrm{rot}}=\left(\begin{array}{cccc}r_{11} & r_{12} & r_{13} & 0 \\ r_{21} & r_{22} & r_{23} & 0 \\ r_{31} & r_{32} & r_{33} & 0 \\ 0 & 0 & 0 & 1\end{array}\right)$

The toppling direction and toppling angle are obtained by applying this rotation to a vertical vector (Eq. A4). The azimuth $\varphi$ of the rotated vector gives the toppling direction, while the angle between the vector and the vertical stands for thetoppling angle $\phi$ (Fig. 4c).

$\boldsymbol{v}_{\text {topple }}=\left(\begin{array}{c}x_{t} \\ y_{t} \\ z_{t} \\ 0\end{array}\right)=\mathbf{M}_{\mathrm{rot}} \cdot\left(\begin{array}{l}0 \\ 0 \\ 1 \\ 0\end{array}\right)$

The matrix associated with this toppling $\mathbf{M}_{\text {topple }}$ can be calculated using the rotation by angles $\alpha$ and $\beta$ around the $x$ and $y$-axes, respectively (Eq. A5).

$$
\mathbf{M}_{\mathrm{topple}}=\left(\begin{array}{cccc}
\cos \beta & 0 & -\sin \beta & 0 \\
0 & 1 & 0 & 0 \\
\sin \beta & 0 & \cos \beta & 0 \\
0 & 0 & 0 & 1
\end{array}\right) \cdot\left(\begin{array}{cccc}
1 & 0 & 0 & 0 \\
0 & \cos \alpha & \sin \alpha & 0 \\
0 & -\sin \alpha & \cos \alpha & 0 \\
0 & 0 & 0 & 1
\end{array}\right)
$$

$\mathbf{M}_{\mathrm{topple}}=\left(\begin{array}{cccc}\cos \beta & \sin \alpha \times \sin \beta & -\cos \alpha \times \sin \beta & 0 \\ 0 & \cos \alpha & \sin \alpha & 0 \\ \sin \beta & -\sin \alpha \times \cos \beta & \cos \alpha \times \cos \beta & 0 \\ 0 & 0 & 0 & 1\end{array}\right)$

with : $\quad \alpha=-\arcsin \left(\frac{y_{t}}{\sqrt{y_{t}^{2}+z_{t}^{2}}}\right)$

and $\beta=\arcsin \left(\frac{x_{t}}{\sqrt{x_{t}^{2}+z_{t}^{2}}}\right)$

Finally, the tilt angle $\psi$ around this toppled vector is calculated by the tilt matrix $\mathbf{M}_{\text {tilt }}$ (Baker, 2009), which is obtained from the total rotation matrix $\mathbf{M}_{\text {rot }}$ and the toppling matrix $\mathbf{M}_{\text {topple }}$ (Eq. A6).

$$
\mathbf{M}_{\text {rot }}=\mathbf{M}_{\text {topple }} \cdot \mathbf{M}_{\text {tilt }} \rightarrow \mathbf{M}_{\text {tilt }}=\mathbf{M}_{\text {topple }}^{-1} \cdot \mathbf{M}_{\text {rot }}
$$

The matrix $\mathbf{M}_{\text {tilt }}$ describing the rotation by an angle $\psi$ around the toppled vector $\left[\mathrm{x}_{t}, \mathrm{y}_{t}, \mathrm{z}_{t}, 0\right]^{T}$ is expressed as follows (Eq. A7) (Baker, 2009). 
$\mathbf{M}_{\mathrm{tilt}}=\left(\begin{array}{llll}1+(1-\cos \Psi) \cdot\left(x_{t}^{2}-1\right) & -z_{t} \cdot \sin \Psi+(1-\cos \Psi) \cdot x_{t} \cdot y_{t} & y_{t} \cdot \sin \Psi+(1-\cos \Psi) \cdot x_{t} \cdot z_{t} & 0 \\ z_{t} \cdot \sin \Psi+(1-\cos \Psi) \cdot x_{t} \cdot y_{t} & 1+(1-\cos \Psi) \cdot\left(y_{t}^{2}-1\right) & -x_{t} \cdot \sin \Psi+(1-\cos \Psi) \cdot y_{t} \cdot z_{t} & 0 \\ -y_{t} \cdot \sin \Psi+(1-\cos \Psi) \cdot x_{t} \cdot z_{t} & x_{t} \cdot \sin \Psi+(1-\cos \Psi) \cdot y_{t} \cdot z_{t} 1+(1-\cos \Psi) \cdot\left(z_{t}^{2}-1\right) & 0 \\ 0 & 0 & 0 & 1\end{array}\right)$

Since it is impossible to calculate an exact analytical solution for $\psi$, the tilt angle is computed by an iterative procedure that minimizes the differences between the tilt matrixes computed with Eqs. (A6) and (A7), respectively.

Acknowledgements. The authors wish to thank M. Frayssines, M. Dessimoz, and A. Pedrazzini from the University of Lausanne for assistance during fieldwork and K. Sudmeier-Rieux and C. Longchamp from the University of Lausanne for correcting and improving the manuscript. The authors are also grateful to J. Hutchinson and three anonymous referees for their reviews and suggestions.

Edited by: K. Chang

Reviewed by: D. J. Hutchinson and three anonymus referees

\section{References}

Abellán, A., Jaboyedoff, M., Oppikofer, T., and Vilaplana, J. M.: Detection of millimetric deformation using a terrestrial laser scanner: experiment and application to a rockfall event, Nat. Hazards Earth Syst. Sci., 9, 365-372, 2009,

http://www.nat-hazards-earth-syst-sci.net/9/365/2009/.

Abellán, A., Vilaplana, J. M., and Martínez, J.: Application of a long-range terrestrial laser scanner to a detailed rockfall study at Vall de Núria (Eastern Pyrenees, Spain), Eng. Geol., 88, 136148, 2006.

Agliardi, F., Crosta, G., and Zanchi, A.: Structural constraints on deep-seated slope deformation kinematics, Eng. Geol., 59, 83102, 2001.

Alba, M., Fregonese, L., Prandi, F., Scaioni, M., and Valgoi, P.: Structural Monitoring of a Large Dam by Terrestrial Laser Scanning, in: Proceedings of the ISPRS Commission V Symposium on Image Engineering and Vision Metrology, edited by: Maas, H.-G. and Schneider, D., Int. Arch. Photogramm. Remote Sens., Dresden, Germany, 25-27 September 2006, XXXVI, Part 5, 6 pp., 2006.

Ambrosi, C. and Crosta, G. B.: Large sackung along major tectonic features in the Central Italian Alps, Eng. Geol., 83, 183-200, 2006.

Baker, M.: 3-D World Simulation - Maths - Axis Angle to Matrix, http://www.euclideanspace.com/maths/geometry/rotations/ conversions/angleToMatrix/index.htm, access: 7 May 2009.

Ballantyne, C. K.: Paraglacial geomorphology, Quaternary Sci. Rev., 21, 1935-2017, 2002.

Bauer, A., Paar, G., and Kaltenböck, A.: Mass Movement Monitoring Using Terrestrial Laser Scanner for Rock Fall Management, in: Geo-information for Disaster Management, edited by: van Oosterom, P., Zlatanova, S., and Fendel, E. M., Springer, Berlin, Germany, 393-406, 2005.

Besl, P. J. and McKay, N. D.: A method for registration of 3-D shapes. IEEE T. Pattern Anal., 14, 239-256, 1992.
Biasion, A., Bornaz, L., and Rinaudo, F.: Laser Scanning Applications on Disaster Management, in: Geo-information for Disaster Management, edited by: van Oosterom, P., Zlatanova, S., and Fendel, E. M., Springer, Berlin, Germany, 19-33, 2005.

Bitelli, G., Dubbini, M., and Zanutta, A.: Terrestrial laser scanning and digital photogrammetry techniques to monitor landslide bodies, in: Proceedings of the XXth ISPRS Congress Geo-Imagery Bridging Continents, XXXV, part B5, Istanbul, Turkey, 12-23 July 2004, ISPRS, 246-251, 2004.

Blikra, L. H.: The Åknes rockslide; monitoring, threshold values and early-warning, in: Landslides and Engineered Slopes. From the Past to the Future Proceedings of the 10th International Symposium on Landslides and Engineered Slopes, 30 June-4 July 2008, Xi'an, China, edited by: Chen, Z., Zhang, J., Li, Z., Wu, F., and Ho, K., Taylor \& Francis Group, London, 2, 1089-1094.

Blikra, L. H., Anda, E., Belsby, S., Jogerud, K., and Klempe, Ø.: Åknes/Tafjord prosjektet: Statusrapport for Arbeidsgruppe 1 (Unders $\varnothing$ king og overvaking), Åknes/Tafjord Project, Stranda, Norway, 57 pp., 2006a.

Blikra, L. H., Anda, E., Høst, J., and Longva, O.: Åknes/Tafjordprosjektet: Sannsynlighet og risiko knyttet til fjellskred og flodbølger fra Åknes og Hegguraksla, Geological Survey of Norway, Trondheim, Norway, NGU report 2006.039, 20 pp., 2006 b.

Blikra, L. H., Longva, O., Braathen, A., Anda, E., Dehls, J. F., and Stalsberg, K.: Rock Slope Failures in Norwegian Fjord Areas: Examples, Spatial Distribution and Temporal Pattern, in: Landslides from Massive Rock Slope Failure, NATO Science Series, 49, edited by: Evans, S. G., Scarascia Mugnozza, G., Strom, A., and Hermanns, R. L., IV. Earth and Environmental Sciences, Springer, Dodrecht, Netherlands, 475-496, 2006c.

Blikra, L. H., Longva, O., Harbitz, C., and Løvholt, F.: Quantification of rock-avalanche and tsunami hazard in Storfjorden, western Norway, in: Landslides and Avalanches: ICFL 2005 Norway, edited by: Senneset, K., Flaate, K., and Larsen, J. O., Taylor \& Francis, London, UK, 57-64, 2005.

Braathen, A., Blikra, L. H., Berg, S. S., and Karlsen, F.: Rock-slope failure in Norway; type, geometry, deformation mechanisms and stability, Norw. J. Geol., 84, 67-88, 2004.

Bugge, A.: Fjellskred fra topografisk og geologisk synspunkt, Norw. J. Geol., 6, 342-360, 1937.

Crosta, G. B., and Agliardi, F.: Failure forecast for large rock slides by surface displacement measurements, Can. Geotech. J., 40, 176-191, 2003.

Derron, M.-H., Blikra, L. H., and Jaboyedoff, M.: High resolution digital elevation model analysis for landslide hazard assessment (Åkerneset, Norway), in: Landslides and Avalanches: ICFL 2005 Norway, edited by: Senneset, K., Flaate, K., and Larsen, J. O., Taylor \& Francis, London, UK, 101-106, 2005.

Eidsvig, U. and Harbitz, C. B.: Åknes/Tafjord prosjektet. Innledende numeriske analyser av flodbølger som følge av mulige skred fra Åkneset, Norwegian Geotechnical Institute, Oslo, Norway, report number 20031100-2, 62 pp., 2005.

Evans, S. G. and Clague, J. J.: Recent climatic change and 
catastrophic geomorphic processes in mountain environments, Geomorphology, 10, 107-128, 1994.

Feng, Q. H., and Röshoff, K.: In-situ mapping and documentation of rock faces using a full-coverage 3-D laser scanning technique, Int. J. of Rock Mech. and Min., 41, 139-144, 2004.

Ganerød, G. V., Grøneng, G., Rønning, J. S., Dalsegg, E., Elvebakk, H., Tønnesen, J. F., Kveldsvik, V., Eiken, T., Blikra, L. H., and Braathen, A.: Geological model of the Åknes rockslide, western Norway, Eng. Geol., 102, 1-18, 2008.

Gordon, S., Lichti, D., and Stewart, M.: Application of a highresolution, ground-based laser scanner for deformation measurements, in: Proceedings of 10th International FIG Symposium on Deformation Measurements, Orange, California, USA, 19-22 March 2001, 23-32, 2001.

Gordon, S., Lichti, D., and Stewart, M.: Structural Deformation Measurement using Terrestrial Laser Scanners, in: Proceedings of 11th International FIG Symposium on Deformation Measurements, Santorini, Greece, 25-28 May 2003, 8 pp., 2003.

Guarnieri, A., Pirotti, F., Pontin, M., and Vettore, A.: 3-D Surveying for structural analysis applications, edited by: Kahmen, H., and Chrzanowski, A., 3rd IAG / 12th FIG Symposium, Baden, Austria, 22-24 May 2006, 6 pp., 2006.

Henderson, I. H. C., Saintot, A., and Derron, M.-H.: Structural mapping of potential rockslide sites in the Storfjorden area, western Norway: the influence of bedrock geology on hazard analysis, Geological Survey of Norway, Trondheim, Norway, NGU report 2006.052, 86 pp., 2006.

InnovMetric: PolyWorks: 3-D scanner and 3-D digitizer software from InnovMetric Software Inc., http://www.innovmetric.com/ Manufacturing/home.aspx, access: 7 May 2009.

Jaboyedoff, M., Baillifard, F., Couture, R., Locat, J., and Locat, P.: New insight of geomorphology and landslide prone area detection using DEM, in: Landslides: Evaluation and Stabilization, edited by: Lacerda, W. A., Ehrlich, M., Fontoura, A. B., and Sayão, A., Taylor \& Francis, London, 191-198, 2004.

Jaboyedoff, M., Couture, R., and Locat, P.: Structural analysis of Turtle Mountain (Alberta) using digital elevation model: toward a progressive failure, Geomorphology, 103(1), 5-16, 2009.

Jaboyedoff, M., Demers, D., Locat, J., Locat, A., Locat, P., Oppikofer, T., Robitaille, D., and Turmel, D.: Use of terrestrial laser scanning for the characterisation of retrogressive landslides in sensitive clay and rotational landslides in river banks, accepted for publication in Can. Geotech. J., 2009.

Jaboyedoff, M., Metzger, R., Oppikofer, T., Couture, R., Derron, M.-H., Locat, J., and Turmel, D.: New insight techniques to analyze rock-slope relief using DEM and 3D-imaging cloud points: COLTOP-3D software, in: Rock mechanics: Meeting Society's challenges and demands, Proceedings of the 1st Canada - U.S. Rock Mechanics Symposium, edited by: Eberhardt, E., Stead, D., and Morrison, T., Vancouver, Canada, 27-31 May 2007, Taylor \& Francis, London, UK, 1, 61-68, 2007.

Jaboyedoff, M., Oppikofer, T., Derron, M.-H., Böhme, M., Blikra, L. H., and Saintot, A.: Complex landslide behaviour controlled by the structures: the example of Åknes, Norway, submitted to Special Publications of the Geological Society of London, 2009.

Kaldhol, H., and Kolderup, N.-H.: Skredet i Tafjord 7 april 1934, Naturvidenskapelig rekke, Bergens museums, Bergen, Norway, 1937.

Kveldsvik, V., Eiken, T., Ganerød, G. V., Grøneng, G., and Ragvin,
N.: Evaluation of movement data and ground conditions for the Åknes rock slide, in: International Symposium on Stability of Rock Slopes in Open Pit Mining and Civil Engineering Situations, 3 April 2006, The South African Institute of Mining and Metallurgy, 279-299, 2006.

Lato, M., Diederichs, M. S., Hutchinson, D. J., and Harrap, R.: Optimization of LiDAR scanning and processing for automated structural evaluation of discontinuities in rockmasses, Int. J. Rock Mech. Mining Sci., 46, 194-199, 2009.

Lichti, D. D., Gordon, S. J., and Stewart, M. P.: Ground-based Laser Scanners: Operation, Systems and Applications, Geomatica, 56, 21-33, 2002.

Lim, M., Petley, D. N., Rosser, N. J., Allison, R. J., Long, A. J., and Pybus, D.: Combined Digital Photogrammetry and Time-ofFlight Laser Scanning for Monitoring Cliff Evolution, The Photogrammetric Record, 20, 109-129, 2005.

Lindenbergh, R. and Pfeifer, N.: A statistical deformation analysis of two epochs of terrestrial laser data of a lock, in: Proceedings of the 7th Conference on Optical 3-D Measurement Techniques, Vienna, Austria, 3-5 October 2005, 2, 61-70, 2005.

Metzger, R., and Jaboyedoff, M.: COLTOP 3-D: A software dedicated to analyze relief using large DEM and massive 3-D-imaging cloud points, Geophysical Research Abstracts, 10, 08785, http://www.cosis.net/abstracts/EGU2008/ 08785/EGU2008-A-08785.pdf, 2008.

Monserrat, O., and Crosetto, M.: Deformation measurement using terrestrial laser scanning data and least squares 3-D surface matching, ISPRS J. Photogramm., 63, 142-154, 2008.

Nordvik, T. and Nyrnes, E.: Statistical analysis of surface displacements - an example from the Åknes rockslide, western Norway, Nat. Hazards Earth Syst. Sci., 9, 713-724, 2009,

http://www.nat-hazards-earth-syst-sci.net/9/713/2009/.

Norwegian Geotechnical Institute: Skredgenererte bølger - En teoretisk gjennomgang med praktiske eksempler, Norwegian Geotechnical Institute (NGI), Oslo, Norway, report number 894031-1, 1992.

Norwegian Geotechnical Institute: Åkernes Landslide - General Description of the Åkernes Slide Area and Control Measures, Norwegian Geotechnical Institute (NGI), Oslo, Norway, report number 585910-9, 1996.

Oppikofer, T. and Jaboyedoff, M.: Åknes/Tafjord project: DEM analysis of the Rundefjellet/Tårnet area, Institute of Geomatics and Risk Analysis, University of Lausanne, report number IGAR-TO-005, 2007.

Oppikofer, T. and Jaboyedoff, M.: Accuracy assessment of terrestrial laser scanning displacement measurements, in preparation for ISPRS J. Photogramm, 2009.

Oppikofer, T., Jaboyedoff, M., Blikra, L. H., and Derron, M.-H.: Characterization and monitoring of the Åknes landslide using terrestrial laser scanning, in: 4th Canadian Conference on Geohazards: From Causes to Management, edited by: Locat, J., Perret, D., Turmel, D., Demers, D., and Leroueil, S., Université Laval, Québec, Qc, Canada, Presse de l'Université Laval, 211218, 2008a.

Oppikofer, T., Jaboyedoff, M., Pedrazzini, A., Blikra, L., and Derron M.-H.: Detailed DEM analysis of rockslide scars to improve the basal failure surface model of active rockslides, in preparation for Eng. Geol., 2009.

Oppikofer, T., Jaboyedoff, M., and Keusen, H.-R.: Collapse at 
the eastern Eiger flank in the Swiss Alps, Nature Geosci., 1, 531-535, 2008b.

Redfield, T. F., Osmundsen, P. T., and Hendriks, B. W. H.: The role of fault reactivation and growth in the uplift of western Fennoscandia, J. Geol. Soc. London, 162, 1013-1030, 2005.

Rocscience: Dips 5.1 - graphical and statistical analysis of orientation data, user manual, Rocscience Inc., Canada, 2007.

Rosser, N. J., Petley, D. N., Lim, M., Dunning, S. A., and Allison, R. J.: Terrestrial laser scanning for monitoring the process of hard rock coastal cliff erosion, Q. J. of Eng. Geol., 38, 363-375, 2005.

Roth, M., and Blikra, L. H.: Seismic monitoring of the unstable rock slope at Aaknes, Norway, Geophysical Research Abstracts, 11, 3680, http://meetingorganizer.copernicus.org/ EGU2009/EGU2009-3680.pdf, 2009.

Selby, M. J.: Controls on the stability and inclinations of hillslopes formed on hard rock, Earth Surf. Proc. Land., 7, 449-467, 1982.

Slob, S. and Hack, R.: 3-D Terrestrial Laser Scanning as a New Field Measurement and Monitoring Technique, in: Engineering Geology for Infrastructure Planning in Europe. A European Perspective, Lecture Notes in Earth Sciences, edited by: Hack, R., Azzam, R., and Charlier, R., 104, Springer, Berlin/Heidelberg, Germany, 179-190, 2004.

Slob, S., van Knapen, B., Hack, R., Turner, K., and Kemeny, J.: Method for Automated Discontinuity Analysis of Rock Slopes with Three-Dimensional Laser Scanning, Transp. Res. Record, 1913, 187-194, 2005.

Stephens, R.: Three-Dimensional Transformations, in: Visual Basic Graphics Programming, 2, John Wiley \& Sons, New York, USA, 419-464, 2000.

Sturzenegger, M. and Stead, D.: Quantifying discontinuity orientation and persistence on high mountain rock slopes and large landslides using terrestrial remote sensing techniques, Nat. Hazards Earth Syst. Sci., 9, 267-287, 2009,

http://www.nat-hazards-earth-syst-sci.net/9/267/2009/.

Sturzenegger, M., Yan, M., Stead, D., and Elmo, D.: Application and limitations of ground-based laser scanning in rock slope characterization, in: Rock mechanics: Meeting Society's challenges and demands, Proceedings of the 1st Canada - U.S. Rock Mechanics Symposium, edited by: Eberhardt, E., Stead, D., and Morrison, T., Vancouver, Canada, 27-31 May 2007, Taylor \& Francis, London, UK, 1, 29-36, 2007.

Terzaghi, K.: Stability of steep slopes on hard unweathered rock, Geotechnique, 12, 251-263, 1962.

Teza, G., Galgaro, A., Zaltron, N., and Genevois, R.: Terrestrial laser scanner to detect landslide displacement fields: a new approach, Int. J. Remote Sens., 28, 3425-3446, 2007.

Teza, G., Pesci, A., Genevois, R., and Galgaro, A.: Characterization of landslide ground surface kinematics from terrestrial laser scanning and strain field computation, Geomorphology, 97, 424437, 2008.

Travelletti, J., Oppikofer, T., Delacourt, C., Malet, J.-P., and Jaboyedoff, M.: Monitoring landslide displacements during a controlled rain experiment using a long-range terrestrial laser scanning (TLS), Int. Arch. Photogramm. Remote Sens., 37, Part B5, 485-490, 2008.

Tsakiri, M., Lichti, D., and Pfeifer, N.: Terrestrial laser scanning for deformation monitoring, in: Proceedings of 12th FIG Symposium on deformation measurements and 3rd IAG symposium on geodesy for geotechnical and structural engineering, Baden, 22-24 May 2006, 10 pp., 2006.

Wyllie, D. C., and Mah, C. W.: Rock Slope Engineering: Civil and Mining, Spon Press/Taylor \& Francis Group, London and New York, UK, USA, 431 pp., 2004. 